\title{
Broad-scale applications of the Raspberry Pi: A review and guide for biologists
}

\author{
Jolle W. Jolles ${ }^{1,2,3}$
}

\author{
${ }^{1}$ Zukunftskolleg, University of Konstanz, \\ Konstanz, Germany \\ ${ }^{2}$ Department of Collective Behaviour, \\ Max Planck Institute of Animal Behaviour, \\ Konstanz, Germany \\ ${ }^{3}$ Centre for Research on Ecology and \\ Forestry Applications (CREAF), Barcelona, \\ Spain

\section{Correspondence} \\ Jolle W. Jolles \\ Email: j.w.jolles@gmail.com

\section{Funding information} \\ Zukunftskolleg, Institute of Advanced \\ study; Alexander von Humboldt-Stiftung; \\ Dobberke Foundation
}

Handling Editor: Chloe Robinson

\section{Abstract}

1. The field of biology has seen tremendous technological progress in recent years, fuelled by the exponential growth in processing power and high-level computing, and the rise of global information sharing. Low-cost single-board computers are predicted to be one of the key technological advancements to further revolutionise this field.

2. So far, an overview of current uptake of these devices and a general guide to help researchers integrate them in their work has been missing. In this paper I focus on the most widely used single-board computer, the Raspberry $\mathrm{Pi}$, and review its broad applications and uses across the biological domain.

3. Since its release in 2012, the Raspberry Pi has been increasingly taken up by biologists, in the laboratory, the field and in the classroom, and across a wide range of disciplines. A hugely diverse range of applications exists that ranges from simple solutions to dedicated custom-build devices, including nest-box monitoring, wildlife camera trapping, high-throughput behavioural recording, large-scale plant phenotyping, underwater video surveillance, closed-loop operant learning experiments and autonomous ecosystem monitoring. Despite the breadth of its implementations, the depth of uptake of the Raspberry Pi by the scientific community is still limited.

4. The broad capabilities of the Raspberry Pi, combined with its low cost, ease of use and large user community make it a great research tool for almost any project. To help accelerate the uptake of the Raspberry Pi by the scientific community, I provide detailed guidelines, recommendations and considerations, and 30+ step-by-step guides on a dedicated accompanying website (http://raspberryp i-guide.github.io). I hope this paper will help generate more awareness about the Raspberry Pi among scientists and thereby both fuel the democratisation of science and ultimately help advance our understanding of biology, from the micro- to the macro-scale.

\section{KEYWORDS}

automation, computing, electronics, open electronics Raspberry Pi, single-board computer, technology, tools

This is an open access article under the terms of the Creative Commons Attribution-NonCommercial-NoDerivs License, which permits use and distribution in any medium, provided the original work is properly cited, the use is non-commercial and no modifications or adaptations are made.

(c) 2021 The Authors. Methods in Ecology and Evolution published by John Wiley \& Sons Ltd on behalf of British Ecological Society 


\section{1 | INTRODUCTION}

The last few decades have seen tremendous technological progress that has transformed biological research (Chave, 2013; Snaddon et al., 2013). Advancements such as automated image-based tracking, bio-logging, genetic barcoding and remote sensing enable us to study plants, animals and ecosystems in more detail and in faster, less intrusive ways than ever before (Anderson \& Gaston, 2013; Dell et al., 2014; Hebert et al., 2003; Hughey et al., 2018; Kays et al., 2015). Driven by the rise of Open Science and global information sharing, new technologies and solutions have become highly accessible (Snaddon et al., 2013), with developments in 3D-printing and low-cost electronics enabling researchers to increasingly build their own laboratory tools (Baden et al., 2015; Pearce, 2014).

Aided by the exponential growth in computer power and capabilities at decreasing costs, recent improvements in sensor technology and battery efficiency, and the rise of the Internet of things (IoT), low-cost single-board computers (SBCs) are predicted to be one of the key technological advancements to further revolutionise biological research (Allan et al., 2018). Developments over the last years have resulted in devices that provide considerable customisation and control, enabling scientists to create research tools and devices that exactly meet their needs (Kwok, 2017; Ravindran, 2020). These low-cost devices furthermore help push the frugality of science, and thereby bring new opportunities for scientific inquiry to the developing world (Reardon, 2013; Whitesides, 2011). A broad uptake and versatile use of low-cost computers by the research community will fuel the development of new methodologies and stimulate interdisciplinary research and new lines of research to open up (Freckleton \& lossa, 2010). Ultimately this will catalyse our understanding of biology (Allan et al., 2018; Hughey et al., 2018) and may help us tackle pressing global issues of ecological and conservation concern (Arts et al., 2015; Pimm et al., 2015).

By far the most popular single-board computer is the Raspberry $\mathrm{Pi}$, with over 37 million units sold since 2012, a huge online community (over 300k users on raspberrypi.org/forums), and educators using it to teach computing to millions of young people around the world (Raspberry Pi Foundation, 2020). Built on open-source principles and driven by the non-profit incentive to increase global access to computing and digital making, this low-cost computer brings together external hardware, sensor and controller interfaces, with user-friendly programming capabilities, high connectivity and desktop functionality (see further Section 2). It is also the most widely used low-cost computer by the biological research community, and is employed in a broad range of projects across diverse topics and research fields. While detailed applications have been described for specific audiences, so far, a broad overview that discusses the wide potential applications of the Raspberry $\mathrm{Pi}$ and a general guide for researchers to help decide if, when and how to use them has been missing.

Here I provide a detailed account of the Raspberry Pi, highlight its advantages and disadvantages, discuss its wide-ranging applications by reviewing papers across the biological domain and provide detailed recommendations, guidelines and considerations to help researchers integrate the Raspberry $\mathrm{Pi}$ in their work. Additionally, detailed step-by-step tutorials (30+, see Table S2 for an overview) are provided on a dedicated website accompanying this paper (raspberrypi-guide.github.io). I hope with this work to raise awareness for the Raspberry $\mathrm{Pi}$ as a versatile, low-cost research tool that can be put to use in almost any situation, and that in turn this will help enhance our understanding of biology from the micro- to the macro-scale.

\section{2 | WHAT IS A RASPBERRY PI?}

The Raspberry Pi (Figure 1) is a low-cost SBC developed by the Raspberry Pi Foundation (raspberrypi.org), a UK-based charity. Since its first release in 2012, several generations of Raspberry Pi computers have been released, which can be categorised in three distinct models: The Raspberry Pi A, B and Zero (a fourth model, the Compute Module, is mainly used in industrial applications). The fundamentals of these three models (henceforth 'Raspberry Pi's') are highly similar (see also Section 5), with each featuring a system-on-a-chip that consists of an integrated CPU (central processing unit) and onchip graphics processing unit (GPU), on-board memory and a power input of $5 \mathrm{~V} \mathrm{DC}$. All models also have a port to connect a dedicated camera, as well as an array of general-purpose input/output (GPIO) pins that can be used to communicate with a wide range of electronics, from LEDs and buttons, to servos and motors, power relays and a huge range of sensors. Special expansion boards that connect to the GPIO pins, called Hardware attached on top (HAT), can provide further functionality, ranging from power management, radiofrequency identification (RFID), motor controllers and high-quality audio recording. Most models also feature an Ethernet connection and wireless (Wi-Fi and Bluetooth) connectivity, which, in combination with the GPIO ports, give the Raspberry Pi huge versatility. The Raspberry Pi has all the functionalities of a standard computer. As such, you can connect a mouse, keyboard and screen without any configuration and have control over an easy-to-use Linux Desktop environment, or other popular operating systems, including

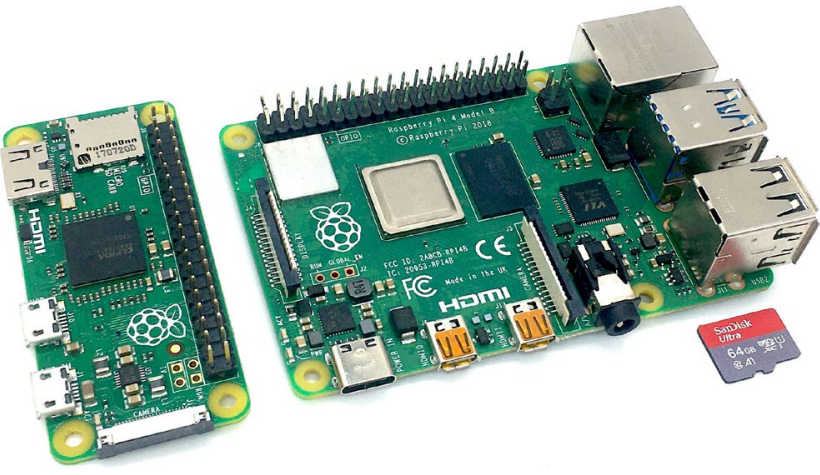

FIGURE 1 A Raspberry Pi zero (left) and 4B (right) with a microSD card for scale 
Windows 10 loT, and Android. The Raspberry Pi can also be used as a headless unit (no keyboard, mouse and screen attached) that can be remotely controlled and programmed to run scripts autonomously using a wide range of computer languages. The Raspberry $\mathrm{Pi}$ is different from a microcontroller, such as the Arduino or the recently released Raspberry Pi Pico, which can be programmed to execute a single user-written program and communicate with sensors and other electronics (see Table 1 for a detailed comparison).

\section{3 | WHY USE THE RASPBERRY PI?}

The Raspberry Pi has been purposefully built as a highly flexible and powerful computer at the fraction of the costs of a traditional PC to be used by anyone to solve problems creatively. Its large number of assets easily outweigh its limitations (Table 2) and make the Raspberry $\mathrm{Pi}$ a great research tool that can be used for almost anything. This can range from interactive and autonomous environmental monitoring and video recording of laboratory experiments, to long-term field measurement stations, and advanced closed-loop devices that can read various input, trigger other actions (e.g. to turn lights or servos on and off) and automatically process data and send warning messages.
Raspberry Pi's may benefit scientists in terms of automated data collection and the acquisition of larger, more extensive and consistent datasets, and thereby help overcome temporal and spatial under-sampling. Furthermore, its remote monitoring capabilities can help reduce potential experimental errors, mitigate human observer biases and minimise disturbances that could otherwise lead to changes in local environmental conditions or a (stress) response in experimental animals (e.g. Gurdita et al., 2016; Lendvai et al., 2015; McBride \& Courter, 2019; Singh et al., 2019). The large number of interfaces and broad connectivity of the Raspberry Pi enable the development of solutions that provide a highly affordable alternative to expensive research equipment that many researchers do not have the budget for (Dolgin, 2018), such as operant conditioning devices, plant phenotyping systems and confocal microscopes (Maia Chagas et al., 2017; Stanton et al., 2020; Tausen et al., 2020). Its low cost also facilitates many devices to be employed simultaneously and enables researchers to try out new ideas, opening the door for creative and novel solutions. Because of its small size, the Raspberry $\mathrm{Pi}$, especially the Raspberry $\mathrm{Pi}$ zero models, can be integrated into almost any experimental set up and easily transported, and with its wide-ranging power options can be left to run autonomously, in the field, for extended periods of time. Finally, self-built Raspberry $\mathrm{Pi}$ systems are highly adaptable as both software and hardware can be

\begin{tabular}{|c|c|c|}
\hline Spec & Raspberry Pi 4B // Zero W & Arduino Uno \\
\hline Type & Single-board Computer & Microcontroller \\
\hline Operating system & Multiple operating systems possible & None \\
\hline Dimensions & $85.6 \mathrm{~mm} \times 56.6 \mathrm{~mm} / / 65 \times 30 \mathrm{~mm}$ & $68.6 \mathrm{~mm} \times 53.4 \mathrm{~mm}$ \\
\hline Weight & $46 \mathrm{~g} / / 9 \mathrm{~g}$ & $25 \mathrm{~g}$ \\
\hline Price & $40(2 \mathrm{~GB})-€ 85$ (8 GB) // €12 & $€ 22$ \\
\hline Multitasking & Yes & No \\
\hline Setting up required & Yes & No \\
\hline Processor & 64-bit // 32-bit & 8-bit \\
\hline Memory & up to $8 \mathrm{~GB} / / 512 \mathrm{MB}$ & $32 \mathrm{~Kb}$ \\
\hline Clock speed & $4 \times 1.5 \mathrm{GHz} / / 1 \mathrm{GHz}$ & $16 \mathrm{MHz}$ \\
\hline Ethernet & Gigabit // Adapter needed & No \\
\hline Wi-Fi & Yes & No \\
\hline Bluetooth & Yes & No \\
\hline USB & $2 \times$ USB $2 \& 3 / /$ micro-USB & No \\
\hline Camera port & Yes & No \\
\hline Audio port & Yes // No & No \\
\hline HDMI & $2 \times / / 1 \times$ micro-HDMI & No \\
\hline Input voltage & $5 \mathrm{~V}$ & $7-12 \mathrm{~V}$ \\
\hline GPIO Ports & $\begin{array}{l}40 \text { pins: } 5 \mathrm{~V}, 3.3 \mathrm{~V} \text {, Ground Digital } \\
\text { I/O }\end{array}$ & $\begin{array}{l}20 \text { pins: } 5 \mathrm{~V}, 3.3 \mathrm{~V}, \text { Ground } \\
\text { Digital, analogue }\end{array}$ \\
\hline Shut down required & Yes & No \\
\hline Storage & MicroSD card (up to $1 \mathrm{~TB}$ ) & flash (32 kb) \\
\hline Desktop interface & Yes & No, $\mathrm{C} / \mathrm{C}++$ required \\
\hline $\begin{array}{l}\text { Power consumption } \\
\text { (idle) }\end{array}$ & $3,000 \mathrm{~mW} / / 750 \mathrm{~mW}$ & $<250 \mathrm{~mW}$ \\
\hline
\end{tabular}

TABLE 1 A comparison of some of the most popular Raspberry Pi and Arduino models 
TABLE 2 Summary of pros and cons of the Raspberry Pi

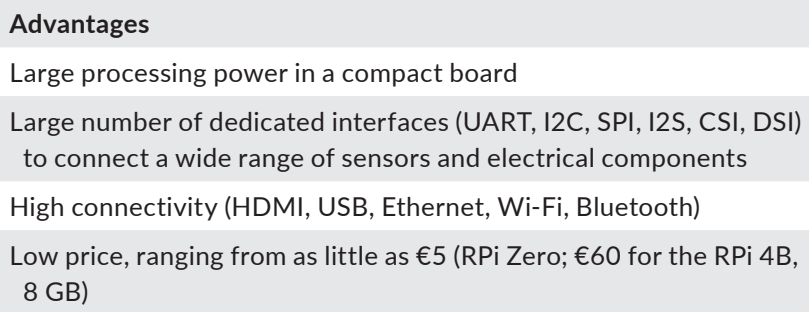

Large processing power in a compact board

Large number of dedicated interfaces (UART, I2C, SPI, I2S, CSI, DSI) to connect a wide range of sensors and electrical components

High connectivity (HDMI, USB, Ethernet, Wi-Fi, Bluetooth)

Low price, ranging from as little as $€ 5$ (RPi Zero; $€ 60$ for the RPi 4B, $8 \mathrm{~GB})$

High ease of use with huge user community, extensive resources, and easy to understand tutorials (see raspberrypi.org)

Works both headless and as a full desktop computer

No extensive programming experience required and small learning curve, but some trial-and-error to be expected

Easy to deploy and highly portable due to its small size

Long-term automated image and video recording with high customisation

Built-in HDMI capable graphics (up to $4 \mathrm{~K}$ for latest models)

Low power consumption (but higher than microcontrollers) and can be powered by wide range of external batteries and solar panels

Contains no moving parts and is silent

High customisability and flexibility compared to commercial solutions

High transferability and backwards compatibility

Disadvantages

Comes as a bare circuit board (but many compact cases are available)

Not as powerful as a traditional PC

More advanced applications will require decent knowledge of programming and electronics, which are not needed for most commercial solutions, but can be learned quickly

No built-in analogue-to-digital conversion (can be added)

No power button or sleep mode (possible with power management HATS)

Custom setups may complicate standardisation and replicability (but can be overcome by detailed standardised online documentation)

easily updated and repurposed when needed. This contrasts with commercial devices, which may become obsolete and no-longer actively maintained, requiring users to stick with old devices or buy new ones.

Besides the Raspberry $\mathrm{Pi}$, a diverse range of other single-board computers exist, including the Odroid, the BeagleBoard, the Banana $\mathrm{Pi}$ and the NVIDIA Jetson Nano. The main downside of these alternatives, many of which mimic the Raspberry $\mathrm{Pi}$ in some way, is that they have limited user support compared to the huge Raspberry $\mathrm{Pi}$ community and the extensive and up-to-date online documentation and tutorials available (see raspberrypi.org). Also, the software and hardware of most Raspberry Pi alternatives tend to not be as actively maintained, and driver support and third-party add-ons to be more limited. Still, for more advanced users and specific cases one of the alternative boards may be preferable, such as those featuring higher computing power or dedicated for machine learning. For some applications it may be preferable to not use a single-board computer at all but a micro-controller instead. Although the Raspberry Pi excels in terms of its processing power, connectivity, usability and access to data storage, microcontrollers are better for running single, repetitive tasks that do not require further user control (Table 1). They also only use a fraction of the energy that a single-board computer may use. It is also possible to run an Raspberry $\mathrm{Pi}$ and microcontroller in parallel to benefit from both their capabilities, such as to use an Arduino for easy analogue sensor readings and a Raspberry $\mathrm{Pi}$ for client-side access, automation and online media sharing. Some potential users may be put off by the fact that the Raspberry $\mathrm{Pi}$ not plug-and-play, and indeed some trial-and-error learning may be expected. But in general the learning curve is quite small and users can count on extensive online support, both for setting up, designing solutions and solving issues. Ultimately, by working with the Raspberry $\mathrm{Pi}$ one may not only gain many practical benefits, it will also help improve computing skills and develop out-of-the-box thinking, a characteristic paramount to scientific progress.

\section{4 | OVERVIEW OF APPLICATIONS ACROSS THE BIOLOGICAL DOMAIN}

To determine how Raspberry Pi's have so far been implemented in biological research, I performed a systematic search using Google Scholar and Web of Science with 'Raspberry Pi' as main keyword (February 2021). To help restrict the search results to biological applications, I ran different searches with keywords related to discipline (e.g. 'plant science', 'wildlife conservation'), type of use (e.g. 'automation', 'remote monitoring') and specific applications (e.g. 'environmental sensing', 'RFID'). I purposefully included papers across the biological domain because certain disciplines are inherently more technologically focused while methodologies are generally broadly applicable. To widen my results, I made sure to carefully check the references of all included papers to find for further relevant work. To obtain the most up-to-date studies, I also included searches on relevant preprint servers (e.g. bioRxiv) and complemented my literature search with public messages on twitter (to 1,700+ followers) calling for researchers to share Raspberry Pi-related work. As it is my aim to investigate the scope of existing Raspberry $\mathrm{Pi}$ applications, I also included unpublished work. Still, despite the broad and extensive literature search, the studies presented are likely an underrepresentation of the actual uptake of Raspberry Pi's as papers do not always clearly mention its use or do so only very briefly. Nevertheless, it is clear that the Raspberry Pi has been increasingly taken up by the biological community since its release (Figure 2) and already a hugely diverse range of applications exists (see Figure 3). Similar literature searches using alternative SBCs (such as the Jetson Nano), revealed very limited uptake so far and will not be further considered. Applications of the Raspberry $\mathrm{Pi}$ are discussed in broad categories below. To provide readers easy consultation of relevant work for current and future projects, a detailed table with an overview of all empirical studies, with a short description, keywords, components and electronics used, and potential study organisms, is provided in Table S1. 


\section{1 | The Raspberry Pi as a dedicated image and video recording device}

One of the foremost uses of the Raspberry $\mathrm{Pi}$ is as a low-cost image and (HD) video recording device. A highly diverse range of applications exists with broad variation in capabilities and complexity. Prinz et al. (2016) used a battery-powered Raspberry Pi recording system to film the behaviour of woodpeckers in cavity nests. Similarly, $\mathrm{H}$. Watson used Raspberry Pi's to record owls' provisioning behaviour (pers. comm. December 2020). Barlow and O'Neill (2020) used Raspberry Pi's to automatically record pollinator visits for thousands of hours at remote field sites based on small-scaled movement detections, while Tu et al. (2016), Jones et al. (2020) and T. Landgraf (pers. comm, December 2020) used Raspberry Pi's to automatically record and detect honeybees at beehives and sugar feeders. Ai et al. (2017) used Raspberry Pi's to film RFID-tagged honeybees from the initial moult for a number of weeks to document the development of the waggle dance. Churchill et al. (2020) used Raspberry $\mathrm{Pi}$ cameras to film the spacing between foraging fruit flies throughout the day. Bjerge et al. (2021) combined multiple light sources with the Raspberry Pi camera to create an automated moth trap to monitor nocturnal insects. Also Leitch et al. (2020) used the Raspberry $\mathrm{Pi}$ as a camera trap but rather to investigate the dispersal of fruit flies. Nazir et al. (2017) describe the Raspberry Pi more generally as the core of a low-cost flexible camera trap platform that can be used for wildlife monitoring. Fink and colleagues (P. Fink, pers. comm. January 2021) used Raspberry Pi's to track the grazing movements of limpets in flowing water over a 2-week period. Johnson, Arrojwala, et al. (2020) used the Raspberry $\mathrm{Pi}$ in combination with depth sensors to automatically measure cichlids' bower construction behaviour over multiple weeks. Spierer et al. (2021) combined the Raspberry Pi camera with a photoresistor to trigger recordings based on changes in light levels to study the climbing behaviour of fruit flies. Wyse et al. (2019) used the Raspberry Pi camera to record the terminal velocity of plant seeds at $90 \mathrm{fps}$ to understand

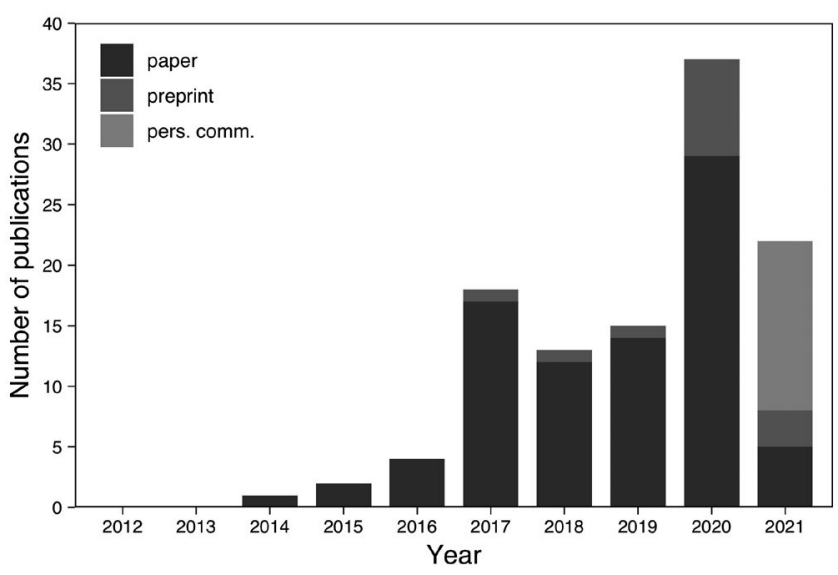

FIGURE 2 Number of empirical studies, across the biological domain, that used the Raspberry $\mathrm{Pi}$, shown per year since the release of the first Raspberry Pi model. Similar studies from the same authors are only discussed in the main text if they described a novel application plant dispersal, while Johnson et al. (2020) integrated it in a custom clamp system to take controlled, magnified images of xylem to investigate drought tolerance in plants. Bontpart et al. (2020) used five connected Raspberry Pi cameras to create a single highly detailed (stitched) image of plant roots to analyse root system development. Saxena et al. (2018) also used a system of linked cameras but used it to acquire video data of rats in a large open space, and used a connected Arduino to accurately synchronise the subunits. Weber and Fisher (2019) continuously recorded the behaviour of multiple mating pairs of captive mice across several reproductive cycles. Maia Chagas et al. (2017) developed an advanced solution that combines a Raspberry Pi, off-the-shelf electronics and 3D-printed mechanical parts to create a basic light and fluorescence microscope (FlyPi) to study the behaviour of small animals such as fruit flies and nematodes (see also Nuñez et al., 2017). Wincott et al. (2020) similarly developed an affordable, portable, automated microscope system using the Raspberry Pi specifically for teaching and outreach purposes. Pollina et al. (2020) present a portable flow-through microscope to study planktonic communities that can be used in remote field locations. Tadres and Louis (2020) used the Raspberry Pi to create a low-cost virtual reality platform (PiVR) that enables highresolution, optogenetic, closed-loop experiments with small freely moving animals at up to $50 \mathrm{~Hz}$. Kallmyer et al. (2019) and Privitera et al. (2020) used the near-IR camera for the automatic tracking of mouse respiration and pupil dilation. Finally, the Raspberry $\mathrm{Pi}$ is also often used for the remote monitoring of animal experiments, helping to minimise potential disturbances (e.g. A. Buatois, pers. comm. January 2021).

\section{2 | High-throughput and long-term recordings of animal behaviour}

A number of studies have used arrays of Raspberry Pi's for controlled and automated high-throughput image and video recording. For example, Todd et al. (2017) used 16 Raspberry Pi's to film the rheotaxis behaviour of zebrafish in small swim tunnels. Jaime et al. (2018) used clusters of Raspberry Pi cameras to monitor the activity of flies housed in tiny 96-well plates. Geissmann et al. (2017) used the Raspberry $\mathrm{Pi}$ as part of an advanced 3D-printed device (Ethoscope) to track and profile fly behaviour in real-time using machine learning, and report the monitoring of 1,400 flies simultaneously using 70 parallel devices. Singh et al. (2019) built a continuous home-cage monitoring system and used the near-infrared camera to automatically classify rodents' sleep-wake cycles and monitor holding conditions and welfare. Jolles et al. (2017, 2019, 2020) used a network of Raspberry Pi's and custom developed software for a range of studies to automatically record the behaviour of large numbers of individuals and groups of fish over time and across different contexts. Martorell-Barceló et al. (2021) filmed individual fish continuously over multiple days to investigate the repeatability of aggressive behaviour, which they extended with deep learning to detect fish automatically over long periods of time (Signaroli, 2020). To 
further investigate the emergence of individual behavioural types, Laskowski, Jolles et al. (pers. comm. December 2020) used an array of 24 Raspberry Pi's to automatically record clonal fish from birth until 4 months of age, continuously, on a second-by-second basis. Alarcón-Nieto et al. (2018) and Wang et al. (2021) used multiple Raspberry Pi's as part of a long-term, automated recording and monitoring system of groups of birds in outdoor aviaries. Finally, Heuschele et al. (2020) automatically filmed copepods in series of cell culture bottles using a single Raspberry $\mathrm{Pi}$ on an automated motor-controlled platform.

\section{3 | Plant phenotyping}

Raspberry Pi's have also been used increasingly as a low-cost, highthroughput solution for plant phenotyping, often coupled with open-source image processing tools and pipelines. For example, Dobrescu et al. (2017) and Valle et al. (2017) used Raspberry Pi's to automatically measure plant growth. Minervini et al. (2017) developed a system using Raspberry Pi's and custom imaging scripts for the automatic phenotyping of rosette-shaped plants (Phenotiki). Similarly, Tovar et al. (2018) used Raspberry Pi's for the automatic imaging of seeds and shoots to quantify plant shape, area, height and colour. Tausen et al. (2020) extended the use of these kinds of phenotyping solutions and implemented a large-scale, automated image-capture system with a total of 180 networked Raspberry Pi's with which they monitored 1,800 individual plants simultaneously over multiple months. Finally, Gaggion et al. (2020) used a single Raspberry $\mathrm{Pi}$ and multiplex board with four cameras to record plant root system growth dynamics over time.

\section{4 | Underwater video surveillance}

A number of studies have implemented the Raspberry Pi in custom solutions for underwater video surveillance. Purser et al. (2020) used 3D-printed components to build a cheap marine camera system capable of deployment to depths of $150 \mathrm{~m}$. Williams et al. (2014) built a stereo motion-triggered camera trap that is deployable at depths up to $300 \mathrm{~m}$. Phillips et al. (2019) used custom 3D-printed pressure housings to record with Raspberry Pi's down to depths of even $5,500 \mathrm{~m}$. By combining the Raspberry Pi Zero with a power management board and a custom battery system, Mouy et al. (2020) were able to record video for up to $212 \mathrm{hr}$ underwater. Lertvilai (2020) built an automated recording device specifically for autonomous zooplankton surveys in the wild. And Hermann et al. (2020) developed
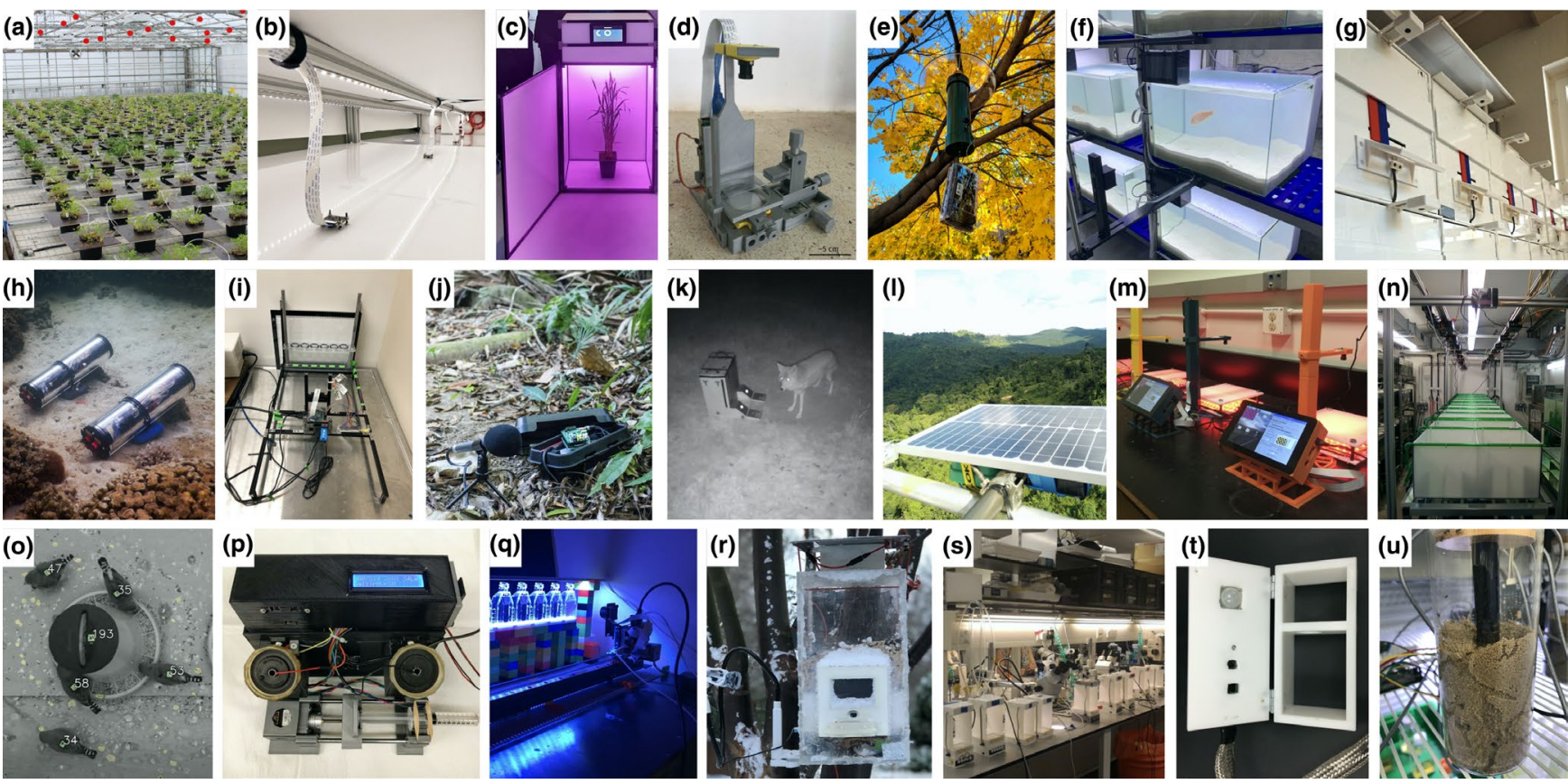

FIGURE 3 A diverse range of Raspberry Pi applications: (a) plant phenotyping (Tausen et al., 2020), (b) high-throughput animal recordings (Jolles et al., 2017), (c) a dedicated plant growth cabinet (Ghosh et al., 2018), (d) a 3D-printed microscope (FlyPi; Maia Chagas et al., 2017), (e) an RFID-equipped birdfeeder (Youngblood, 2020), f) long-term monitoring of fish behaviour (Martorell-Barceló et al., 2021), (g) automated bird puzzle boxes (Chimento et al., 2021), (h) an autonomous underwater camera system (Lertvilai, 2020), (i) automated quantification of fly climbing behaviour (Spierer et al., 2021), (j) a field audio recorder for bioacoustics (Bradfer-Lawrence et al., 2019; Whytock \& Christie, 2017), (k) an operant conditioning device for wild mesocarnivores (Stanton et al., 2020), (I) autonomous ecosystem monitoring (Sethi et al., 2018), (m) closed-loop virtual reality (Tadres \& Louis, 2020), (n) long-term recording of fish from birth (K. Laskowski \& J. Jolles, pers. comm. January 2021), (o) long-term monitoring of captive bird flocks (Alarcón-Nieto et al., 2018), (p) an operant licking device (Longley et al., 2017), (q) autonomous motor-controlled video recording (Heuschele et al., 2020), (r) a smart birdfeeder to collect behavioural and environmental data (Philson et al., 2018), (s) high-throughput ethomics (Geissmann et al., 2017), (t) real-time measurements of mouse activity, body temperature and respiratory rate (Kallmyer et al., 2019) and (u) measurement of respiration of nest-building ants (A. Rathery, pers. comm. 2021) 
a continuous underwater monitoring system that can be connected to and viewed remotely by means of a surface unit.

\section{5 | Electronic sensing and control to study animal behaviour and physiology}

Scientists have widely used the Raspberry $\mathrm{Pi}$ in combination with electronic sensors and actuators, in particular to study animal behaviour and physiology. For example, Longley et al. (2017) and Pasquali et al. (2017) used infrared-motion detectors to monitor the activity levels of rats and arctic invertebrates respectively. Kallmyer et al. (2019) used a thermal camera to monitor mouse body surface temperature, while Vickers and Schwarzkopf (2016) used temperature sensors to directly estimate transient body temperatures of small lizards. Brem et al. (2020) used the Raspberry Pi and thermocouple probes to study hibernation phenotypes of meadow jumping mice. Ardesch et al. (2017) used captive touch sensors to study rodents' walking behaviour. A. Rathery (pers. comm. January 2021) used $\mathrm{CO}_{2}$ sensors to measure the metabolic rate of ants digging nests at different temperatures. Dan Killam (pers. comm. May 2021) used magnetic sensors and an Arduino linked to a Raspberry $\mathrm{Pi}$ to measure the opening and closing of the valves of clams in situ. Raab et al. (2021) even used the Raspberry Pi to monitor the electric behaviour of electric fish, including in remote locations in the Columbian jungle using car batteries. Noorshams et al. (2017) controlled special load cells with the Raspberry Pi to get automatic weigh measurements of RFID-tagged mice (see also Bolaños et al., 2017). Youngblood (2020) set up birdfeeders with RFID readers for the remote monitoring of wild bird populations, while Ferreira et al. (2020) used an RFID-equipped birdfeeder to automatically generate a large labelled dataset of bird photos for machine learning. Similarly, Meniri et al. (2019) used an RFID reader to help automatically trap pit-tagged bats. Ripperger et al. (2020) describe the Raspberry Pi as a central element of a custom-build wireless biologging network, and Marshall et al. (2018) used the Raspberry Pi as the main database server to communicate with handheld devices for a long-term field project to study banded mongooses.

A number of studies further implemented actuators or controlled electronic components in their custom applications. For example, Charlton and Merritt (2020) used haptic motors to vibrate aquaria to investigate bioluminescence in glow-worm larvae. Hol et al. (2020) linked Raspberry Pi's to peltier elements to regulate the temperature of an artificial substrate to study mosquito's biting behaviour Similarly, M. Stockenreiter (pers. comm. December 2020) used Raspberry Pi's to control heating mats to investigate the effects of increased temperature on cyanobacteria in natural plankton communities. Reemeyer and Rees (2020) used a galvanic oxygen sensor to control the nitrogen flow in aquaria to investigate the influence of dissolved oxygen on fishes' metabolism. M. King (pers. comm. December 2020) used stepper motors to simulate the tides to investigate their influence on the (social) behaviour of marine arthropods. Philson et al. (2018) used the Raspberry Pi to build an automated bird feeder that dispenses food using a servo-controller when a proximity sensor detects a bird. Finally, M. Oellermann (pers. com. January 2021) used the Raspberry Pi as part of a shuttle box system that automatically controls pumps and heaters based on an animal's position to measure their thermal preferences.

\subsection{Autonomous learning experiments}

A broad range of studies have used the Raspberry Pi to create devices dedicated to facilitate controlled and autonomous learning experiments. Some of the most advanced solutions are capable of performing tasks similar to those executed by high-end commercial systems. For example, O'Leary et al. (2018) built an advanced yet low-cost touchscreen operant chamber whereby an image is presented that, when touched by a rat, results in the release of food, a specific tone to be played and a LED light to be turned on, while food collection is detected using an IR sensor (see also Gurley, 2019). Buscher et al. (2020) also built a sophisticated operant chamber system using the Raspberry $\mathrm{Pi}$ that has electro-physiological and optogenetic compatibility. Longley et al. (2017) built a rodent licking device using a capacitive touch sensor, a syringe pump and a LED light to study operant conditioning. And Silasi et al. (2018) used the Raspberry Pi to develop a forelimb motor task and via an integrated RFID-tag reader autonomously and individually trained socially housed mice.

Chimento et al. (2021) used Raspberry Pi's for the automatic control and monitoring of pit-tagged birds solving puzzle boxes. Similarly, L. Zandberg et al. (pers. comm. January 2021) used Raspberry Pi's as operant feeders to enable individual training on auditory cues of group-living birds in the laboratory and field. Stanton et al. (2020) developed an automated device to administer reversal learning tests to raccoons, skunks and coyotes without needing extensive training or the involvement of an experimenter. Arce and Stevens (2020) integrated the Raspberry Pi with an automatic dog food dispenser and a touchscreen device to create an operant system to study canine cognition. A number of groups have also used the Raspberry Pi for automated learning and discrimination tasks with fish, including the presentation of lights or images on LCD screens and the automatic release of food rewards from modified fish feeders (Lucon-Xiccato et al., 2019; Wallace et al., 2020; W. Toure, pers. comm. January 2021). Raspberry Pi's are also currently used for visual learning tasks with mantis shrimp to investigate spectral sensitivity (M. J. How, pers. comm. January 2021). Finally, Sehdev et al. (2019) used Raspberry Pi's and automated rotating platforms as part of an automated learning and memory assay for walking flies.

\section{7 | Bio-acoustics}

The Raspberry $\mathrm{Pi}$ has been used as a dedicated audio recorder for bioacoustics, including for biodiversity and habitat assessments. Whytock and Christie (2017) developed a set up consisting of a 
battery-powered Raspberry $\mathrm{Pi}$, a dedicated audio card, an external microphone and custom scripts to record audio of various habitats and vocalisations of birds and bats for long periods of time (>1 month). Bradfer-Lawrence et al. (2019) employed these devices successfully to acquire acoustic indices for 117 sites in Panama, and similar solutions have been used in other follow-up studies, such as to investigate the impacts of land use and organic farming on bird diversity and vegetation structure (Dröge et al., 2021; Myers et al., 2019). Furthermore, Beason et al. (2019) combined the system of Whytock and Christie with a dedicated bat audio recorder for the automatic recording of ultrasonic bat calls. Sethi et al. (2018) describe a solarpowered system based on the Raspberry Pi to record audio in remote field locations in Borneo over long periods of time and send data directly to the internet over the $3 \mathrm{G}$ phone network, including to stream to a public-facing website (Sethi et al., 2020). Similarly, the Orcasound project uses a Raspberry $\mathrm{Pi}$ and connected hydrophones to provide live streams of underwater recordings to help identify killer whales and other underwater sounds using citizen science. Caldas-Morgan et al. (2015) combined the Raspberry Pi with a custom-build hydrophone and a USB audio codec placed in a waterproof enclosure for autonomous underwater recordings. Lendvai et al. (2015) built a lowcost automated playback and recording system, by combining the Raspberry Pi with an RFID reader to measure the responses of tree swallows to begging calls in the field. Finally, Wilhite et al. (2020) used a Raspberry $\mathrm{Pi}$, an amplifier, and outdoor speakers for the playback of bird calls in the field to help assess how acoustic recording devices can help quantify bird populations.

\section{8 | Environmental monitoring}

A number of research groups have used Raspberry Pi's for the (longterm) monitoring of environmental conditions in the laboratory (e.g. Gurdita et al., 2016; Longley et al., 2017; Wilshin et al., 2018), and in greenhouses and plant growth chambers (e.g. Cabaccan et al., 2017; Grindstaff et al., 2019; Shah \& Bhatt, 2017), including accurate detection of environmental temperature, humidity, barometric pressure and light levels. Especially in combination with automated messaging services, such as to notify experimenters when variables go out of range (e.g. Grindstaff et al., 2019; Gurdita et al., 2016; Tausen et al., 2020), this helps minimise fluctuations in environmental factors that may influence experiments or the behaviour of animals, and thereby improves the accuracy and reproducibility of experiments. Building on these capabilities, Ghosh et al. (2018) developed a special plant growth cabinet (Growcab) that uses the Raspberry $\mathrm{Pi}$ to help control light quality, intensity and photoperiod to optimise speed breeding parameters. McBride and Courter (2019) and Philson et al. (2018) automatically acquired temperature, wind speed and humidity of the micro-climates around birdfeeders in the field, and, using a manual sensor connected to a Raspberry Pi, Bardunias et al. (2020) made use of a Raspberry Pi to measure the humidity of termite mounds in the Namibian desert. Leitch et al. (2020) used the Raspberry Pi to connect data on wind speed using a connected

\section{BOX 1 The Raspberry Pi as a tool for teaching}

In addition to its use in research, the Raspberry $\mathrm{Pi}$ is a great tool for teaching. Indeed, the Raspberry Pi was explicitly developed with the main aim to bring and teach computing and open electronics and its wide-ranging possibilities to people around the world. This is particularly the case for the fields of science, technology, engineering and mathematics (STEM), as by building their own devices, students learn the basics of electronics, programming, biology and physics. Besides using the Raspberry Pi as a way to teach the basics of computational science (Fletcher \& Mura, 2019), it can be used specifically to teach about the scientific process, from designing experiments, building instruments, collecting and analysing data, to interpreting results. Students could be presented with a scientific question and asked to solve it using a Raspberry Pi. Tasks could also focus on specific elements, such as to use a Raspberry Pi to teach about data collection (e.g. A. Halbritter, pers. comm. December 2020) or analysis (e.g. Tovar et al., 2018). An example is SCOPES (Sparking Curiosity through Opensource Platforms in Education and Science), a modular education platform that uses Raspberry Pi's to communicate subjects from genetics to neurobiology and provides students the opportunity to design, perform and share scientific experiments (Beattie et al., 2020). Such a handson approach is superior for learning compared to more classical unidirectional teaching approaches (Miller, 2015). Unsurprisingly, an increasing number of organisations have been pushing free open-source hardware (FOSH) solutions for education (see Maia Chagas, 2018). A diverse collection of teaching resources can be found on raspberrypi.org.

anemometer. Finally, Griffiths et al. $(2017,2020)$ rigged kayaks with underwater environmental sensors and a GPS sensor for the finescale mapping of the acoustic environment as well as for artistic purposes. In general, autonomous environmental monitoring solutions using the Raspberry Pi seem relatively underused, despite their great potential (see e.g. Sethi et al., 2018).

\section{5 | GUIDELINES, POINTERS AND CONSIDERATIONS FOR IMPLEMENTING THE RASPBERRY PI}

This section gives a practical overview of how to implement the Raspberry $\mathrm{Pi}$, providing information for both complete beginners and more experienced users. A range of detailed step-by-step tutorials $(30+)$ can be found on the website raspberrypi-guide.github.io accompanying this paper, of which a detailed overview is provided in Table S2. 


\section{1 | What hardware do you need?}

As a minimum (see Figure 4 for an overview), one only needs a Raspberry $\mathrm{Pi}$, a microSD card for storing the operating system and any user data (at least $8 \mathrm{~GB}$ ), and a power supply of $5 \mathrm{~V} D C$ (at least 2.5 A). The best model for your project depends strongly on the processing power and connectivity required (see below). A keyboard, mouse and computer screen are also generally recommended for first-time users, of which many small, highly affordable versions are on the market, and, although not actually needed, recommended to have as backup, including additional Raspberry Pi's, microSD cards and chargers where possible for flexibility and testing. The Raspberry $\mathrm{Pi}$ Touchscreen is a nice troubleshooting tool, such as when you are not able to connect to your Raspberry $\mathrm{Pi}$. No additional hardware is needed for most straight-forward uses, but when building custom electronic solutions, some or all of the following could be needed: electrical tape, wire cutters, pliers, bread boards, jumper wires, standard electrical wire, soldering equipment, and heat shrink sleeves and a heat gun (see Figure 4). Also, a soldering helping hand and a multi-meter may come in handy. These tools and electronics are widely available in both online and retail stores. When building custom solutions, aluminium profiles (e.g. from Makerbeam) are a great way to create sturdy, organised systems. Finally, access to a 3D printer could help building custom structures and encasings, such as for cameras and other sensors and to keep all components sturdy into place.

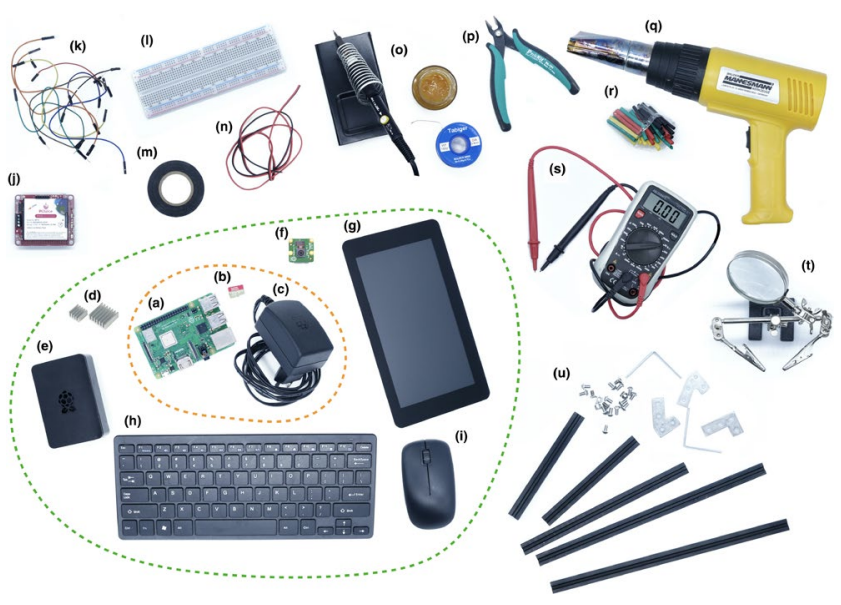

FIGURE 4 An overview of everything you may need to get started, with bare essentials in orange and recommended equipment in green: (a) Raspberry $\mathrm{Pi}(€ 6$ for the Zero to $€ 80$ for the 4B-8 GB model), (b) microSD card (from €6 for $16 \mathrm{~GB}$ ), (c) compatible power source $(€ 10)$, (d) heatsink (from $€ 1$ ), (e) case $€ 5$ $€ 10)$, (f) Raspberry Pi camera ( €30), (g) (touch) screen (from €45), (h) keyboard (€15-€30), (i) mouse (from €10), (j) power management HAT (€55), (k) jumper wires ( $€ 5$ for 40 ), (I) breadboard (€3-€7), $(m)$ electrical tape $(\sim € 2)$, ( $n$ ) electrical wire (from $€ 4)$, (o) soldering kit (from $€ 15$ ), (p) wire cutters (€6), (q) heat gun (from $€ 30$ ), ( $r$ ) heat shrink sleeves (kit: €2-€10), (s) multi-meter (from €15) and ( $t$ ) helping hand (€7-€20), (u) makerbeam profiles (kit: €85). Prices in brackets are approximations
The different models of Raspberry $\mathrm{Pi}$ are all built with broadly the same functionality but differ considerably in processing speed, power requirements and connectivity. At the time of writing, the Raspberry $\mathrm{Pi} 4 \mathrm{~B}$ is the fastest model, both in terms of its computing power (quad-core $1.5 \mathrm{GHz}$; 2-8 GB RAM) and its connectivity, due to its USB 3.0 ports (read/write speeds up to $300 \mathrm{Mbps}$ ), highspeed Gigabit Ethernet (900+ Mbps) and Wireless LAN (up to 100 Mbps). It is, however, also the most power hungry ( 3.4 $\mathrm{W}$ on average; Zwetsloot, 2019). The Raspberry Pi Zero (W) is half the size, lacks a considerable part of the connectivity (see Table 1), and has much lower processing power (single-core $1 \mathrm{GHz}$; 512 MB RAM), but only needs $0.8 \mathrm{~W}$ at idle, making it ideal for simpler, battery-powered solutions. The Raspberry Pi $3 \mathrm{~A}+$ is an in-between model for users that seek to balance performance with power requirements. The Raspberry Pi 400 is a Raspberry Pi 4B integrated in a keyboard and lacks a camera port and hence best for Desktop use. Machine learning is possible with the more powerful Raspberry Pi models, but a dedicated Neural Compute Stick is still needed for object detection in real-time.

\section{2 | Installing and configuring the operating system}

Installing and configuring the operating system on the Raspberry $\mathrm{Pi}$ is nowadays very straight forward. Using another computer, simply download the Raspberry Pi Imager (raspberrypi.org/downloads/), plug in the microSD card, and select the desired operating system. The latest version of Raspberry Pi OS (previously called Raspbian) with Desktop is recommended. After the SD card is written, plug it in the Raspberry Pi and start it up by connecting power (for a detailed tutorial with further options see Table S2). An alternative is to buy an SD card preloaded with an installable version of the operating system (an SD card with 'NOOBS'). Now to be able to connect, you will need a screen, keyboard and mouse. However, with a couple of simple additional steps it is also possible to immediately run your freshly installed SD card without these peripherals (for tutorial, see Table S2). Upon first boot in the Raspberry Pi OS Desktop environment, you will be guided through a short series of steps to help configure and update your system, but some additional configuration steps and security measures are recommended (for tutorials, see Table S2). It is also quite straightforward to clone the SD card to not have to go through all steps of setting up your device again, such as when you want to create (a network of) identical units (see below). Make sure you always shut down the Raspberry Pi before you disconnect power to avoid losing data and potentially corrupt the system.

\section{3 | Controlling the Raspberry Pi}

The Raspberry Pi can be controlled like any other desktop computer using a keyboard, mouse and monitor, but there are also various ways to command the Raspberry Pi remotely. SSH (Secure Shell) 
enables control from another device on the same network using the command line. It is pre-installed on Linux, Mac and some Windows operating systems and can also be installed on mobile devices (for tutorial see Table S2). It is even possible to command multiple Raspberry Pi's at once using a single terminal window, such as with csshX. If you need to use the graphical Desktop interface or are not comfortable using the command line, Virtual Network Computing (VNC; Figure 5) is a great alternative. It allows you to remotely control the desktop interface of the Raspberry Pi from anywhere without the need for a monitor (for tutorial, see Table S2). Raspberry Pi OS comes with RealVNC Connect software, so all you need to do is to install the VNC Viewer software on the other device you are connecting from. Besides direct connections on a private network, also end-to-end encrypted cloud connections are possible (free for non-commercial use). To help create secure remote access to your Raspberry $\mathrm{Pi}$ in other ways, such as to connect to the terminal or provide a local webserver, a number of other services exist, including remote.it, ngrok and dataplicity.

\subsection{Wired and wireless connectivity}

The Raspberry Pi models differ in their connectivity, with some lacking an Ethernet port and/or Wi-Fi capabilities. Whether to use an Ethernet or wireless connection will depend on the needs of your project. The main benefits of a wireless connection are greater flexibility in positioning the Raspberry $\mathrm{Pi}$ and no need for Ethernet cables. However, wireless networks can have issues with interference and do not have the stability and bandwidth that a wired connection can provide. Also, when using an Ethernet connection with a PoE HAT no dedicated power supply is needed (see below), facilitating (indoor) positioning.

By default, the Raspberry Pi will be given a dynamic IP address when connected to a (local) network, which makes it easy to get connected. Although such a dynamic address should be fine for most uses, in some cases it is recommended to create a static IP address to ensure a consistent connection (for tutorial, see Table S2).

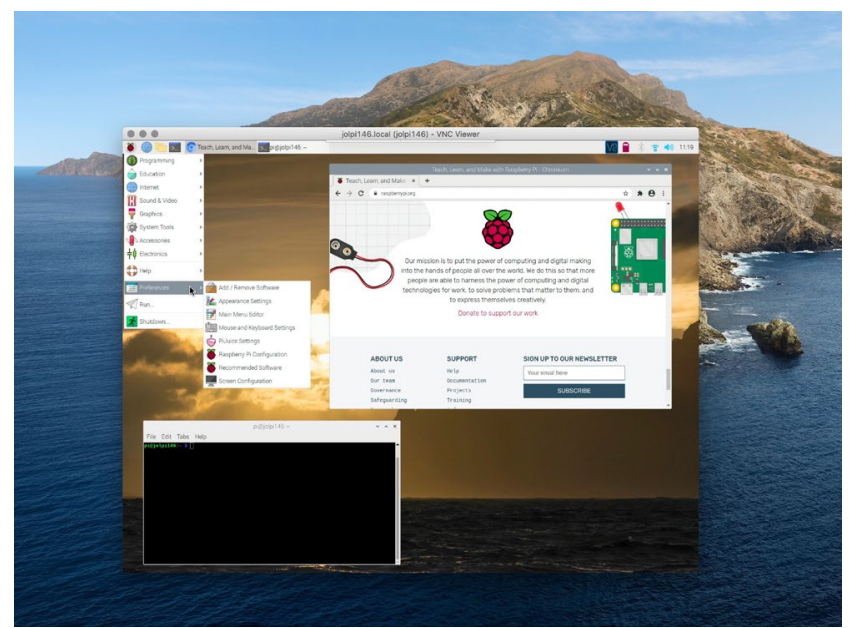

FIGURE 5 Virtual Network Computing is a great way to remotely control your Raspberry $\mathrm{Pi}$
When working with arrays of Raspberry Pi's, it is also best to set up a dedicated local area network (LAN) with a specific subnet to which individual Raspberry Pi's can be easily added. A centralised computer can then be used to command all Raspberry Pi nodes and enable communication via the internet (for tutorial, see Table S2). Such a system has been used successfully for systems of up to 180 units (Tausen et al., 2020), and can be programmed to perform hardware-intensive experiments in a distributed and scalable way (e.g. Saunders \& Wehr, 2020). When your Raspberry Pi is primarily connected to the internet, it is recommended to install a firewall to keep your Raspberry Pi secure (for tutorial, see Table S2).

In some cases, one may want a more direct connection with the Raspberry Pi, such as when neither a wireless nor a wired network is available. The first option is to configure a direct computerto-computer connection using an Ethernet cable (for tutorial see Table S2). The second option is to set up the Raspberry Pi as an access point that generates its own Wi-Fi network to which the host device can connect. This is ideal for remote field systems, but does require some configurating via the terminal (for tutorial, see Table S2). Long-range high-gain Wi-Fi dongles can help increase the network range of the Raspberry Pi, which can be more than $150 \mathrm{~m}$ when there are no obstructions (pers. obs.). It is also possible to connect the Raspberry Pi to the internet using a mobile network dongle, such as the Huwaii E8372. You will need a sim card and data plan with a phone company, but then it is mostly just plug-and-play. This is a great option as it will enable you to set up your Raspberry Pi to send data from anywhere, such as from the Bornean rainforest (see Sethi et al., 2020), as long as a phone network is available. Longdistance radio frequency technologies such as LoRa, which enable the transfer of very small data packages over longer distances, may also be useful for some projects.

\section{5 | Powering the Raspberry $\mathrm{Pi}$}

\subsection{1 | Power supply}

There are various ways to power the Raspberry Pi. The standard charger supplied by the Raspberry Pi foundation is recommended for most uses, although any charger should work as long as it supplies $5 \mathrm{~V} \mathrm{DC}$ with a minimum of $2.5 \mathrm{~A}$, depending on what peripherals are connected. For the laboratory, and especially when working with arrays of Raspberry Pi's, a good alternative is Power over Ethernet (PoE). PoE provides power via the Ethernet cable and allows a networked device to be automatically turned on and off remotely. By not requiring a dedicated charger, it furthermore provides flexibility in the positioning of the device as nearby power sockets are not needed and reduces cable clutter. A PoE HAT and PoE-capable network switch/injector will, however, be required. The Raspberry $\mathrm{Pi}$ can also run on most USB powerbanks, and on $12 \mathrm{~V}$ batteries with use of a DC/DC Step Down converter. AGM and lithium-ion batteries are preferable over standard lead-iron batteries because of their smaller size and possibility to be positioned in any orientation. 
However, it should be noted that batteries in practice supply less than their stated capacity, that capacity reduces over a battery's lifetime, and that batteries can only be discharged to a certain level. It is also possible to run the Raspberry Pi on solar energy. A small $5 \mathrm{~V} 6 \mathrm{~W}$ solar panel can suffice for the most basic requirements, and larger, more permanent systems can be an ideal solution for many field systems, such as including a $12 \mathrm{~V} / 18 \mathrm{~V} 50 \mathrm{~W}$ solar panel, a solar charger and a 12 V battery (see Proppe et al., 2020; Sethi et al., 2018).

\subsection{2 | Power management}

The Raspberry Pi has no native power management program that enables power supply monitoring and automatisation. This means that when the supplied DC power is too low, such as with unreliable power sources, or power drops completely, the Raspberry $\mathrm{Pi}$ will turn off abruptly, with the risk of losing data and corrupting the SD card. A number of HATs exist, such as the PiJuice, Sleepy Pi and WittyPi, that provide power management tools. These HATs can augment the DC power supply from a battery such that fluctuating DC power sources, such as from a connected solar panel, can be utilised effectively. They can also help create an uninterrupted power supply (UPS), such that in the case of a power outage it will automatically switch to battery input. Power management HATs also enable intelligent wake-up modes and the automated initiation of user-defined scripts (for a tutorial, see Table S2), which, in combination with the true low power deep sleep state $(<1 \mathrm{~mA})$, can help to considerably reduce power consumption.

\subsection{3 | Power consumption}

In general, Raspberry Pi's consume little power, with the most powerful model (currently the RPi 4B) under load consuming about the same as a LED light bulb (5.5 W). However, for battery-powered projects this can still quickly rack up. A first thing to consider when trying to reduce power consumption is the model used (see above). Although faster models may consume more energy, they will also do the work more quickly, so the optimal model will ultimately depend on the kind of task and how often it needs to be performed. Besides using a power management HAT to reduce uptime, various procedures can help reduce power consumption even further (for tutorial, see Table S2).

To estimate how much power your Raspberry Pi project requires, and help decide on the appropriate size of your batteries and solar panel, first determine your expected average power consumption based on your model, added peripherals and expected processing power. Also take power loss into account when transferring energy. For example, a Raspberry $\mathrm{Pi} 3 \mathrm{~A}+$ recording video will require about $350 \mathrm{~mA}$ (half that of the 4B model). A 12,000 mAh battery with $80 \%$ efficiency could run this unit for about $27 \mathrm{hr}$. If you only need the device a couple of hours each day and make use of a power management HAT to put it in deep sleep the rest of the day, you could use the same battery to power the device for 9 days.
To estimate the minimum size of a solar panel to power your project, first calculate the expected power consumption per day in Watt hours. Now calculate the minimum capacity of the system based on the expected hours of sun per day, the number of days the system should be able to run without sun, and accounting for power loss in the system. For example, when there is $5 \mathrm{hr}$ of expected sun per day, the system should be able to run 3 days without any sun, and energy efficiency is $70 \%$, then the solar panel should be at least $6 \mathrm{~W}$ $((0.35 \mathrm{~A} \times 3 \mathrm{hr} \times 5 \mathrm{~V}) \times 4$ day/0.7/5). Real-life power consumption tests with your system are recommended before putting it to use (see Proppe et al., 2020 for further information).

\section{6 | Recording images and video}

\subsection{1 | Official camera modules}

All Raspberry Pi Models (except the 400) feature a Camera Serial Interface to connect a camera module via a ribbon cable to the board. Two camera models are offered by the Raspberry Pi foundation, the v2 camera board (which supersedes the v1 5 MP camera board) with an 8 MP sensor, and the twice as expensive high-quality (HQ) camera with a $12 \mathrm{MP}$ sensor. The HQ camera can connect C- and CS-mount interchangeable lenses and, with a lens mount adapter, even DSLR lenses can be used. This enables huge flexibility in terms of the field-of-view and thus positioning of the camera (for a tutorial to optimally position the camera, see Table S2) and facilitates accurately setting the camera focus, which is difficult with the tiny v2 camera. A benefit of the latter model is that it does not condensate and is therefore more robust to environmental conditions. The v2 camera board is also available as an infrared model (Pi Noir) that can capture near-IR wavelengths up to $1,000 \mathrm{~nm}$. Although there is no infrared version of the HQ Camera, its IR Filter can be removed.

The HQ camera can record still images at a higher resolution $(4,056 \times 3,040$ pixels $)$ than the $v 2$ models $(3,280 \times 2,464$ pixels $)$. However, as it is the GPU hardware not the camera that sets the video recording limits, the video recording capabilities of the cameras are actually the same, with 1,080p at $30 \mathrm{fps}, 720 \mathrm{p}$ at $60 \mathrm{fps}$ and $640 \mathrm{p}$ at $90 \mathrm{fps}$. Although image quality tends to be higher for the HQ camera, detailed testing shows that, with some effort, images taken with the $\mathrm{v} 2$ camera can be similarly sharp (pers. obs.), and sharp enough to track small barcodes on moving birds and fish (e.g. Alarcón-Nieto et al., 2018; pers. obs.). Both camera modules can also be connected to a microscope and, using custom 3D solutions whole-slide imaging is possible (see e.g. github.com/python-friends/auto-scope), facilitating image and video recording at the microscopic scale.

\subsection{2 | Alternative camera options}

Besides the official Raspberry Pi camera modules, a variety of thirdparty camera modules exists, some of which even come with their own IR lights. The most advanced cameras are from Arducam, which 
offer a whole suite of cameras, some of which can record up to 16 megapixels, but which may require special software. Most third-party alternatives only offer $5 \mathrm{MP}$ resolution, which may not be an issue if recording video (see above). Also a range of cameras is available equivalent to the $\mathrm{v} 1.5 / \mathrm{v} 2$ camera model but with a $\mathrm{C}(\mathrm{S})$ mount as well as the cheaper M12 mount. Although camera modules tend to come with a standard $15 \mathrm{~cm}$ ribbon cable, lengths of $5 \mathrm{~cm}$ to $200 \mathrm{~cm}$ are also available, increasing the flexibility for positioning the camera. Rather than using a camera module, it is also possible to use a standard USB webcam (for tutorial, see Table S2). Note, however, that the configurability of the camera modules is superior to that of USB webcams and, at the time of writing so is their image quality. Finally, it is also possible to connect and control a DSLR from the Raspberry Pi, such as using the gphoto2 library, which may help provide increased image quality but with limited flexibility and configurability.

\subsection{3 | Recording software}

There are a variety of software solutions to record with the Raspberry Pi. First, one can control the camera module directly from the command line with the native raspicam command line tools, which include raspistill to take still images and raspivid for videos. These provide a wide range of recording options, including the possibility to preview the camera stream, adjust the camera settings (e.g. contrast, brightness, saturation, iso, shutter speed), and set exposure mode and white balance. Recording commands have to be written on a single line but can be integrated in bash scripts for automated recordings. picamera (picamera.readthedocs.io; Jones, 2018) provides a pure Python interface to the Raspberry Pi camera module, greatly facilitating users to write their own recording scripts, including to record and stream videos, capture consistent images and timelapses, or record to NumPy arrays for immediate processing. pirecorder (jollejolles.github.io/pirec order/; Jolles, 2020), which builds on picamera, was specifically developed with scientists in mind, and provides a simple-to-use solution to run controlled and automated image and video recordings using optimal settings. It facilitates setting up and configuring the Raspberry $\mathrm{Pi}$ camera using interactive video stream functionalities, and enables the starting, scheduling and converting of a wide range of recordings using simple commands. Motion (motion-project.github.io) is a highly customisable command line tool to monitor video signals with motion detection, with MotionEye providing a user-friendly web frontend to control the motion software from the browser (see also github.com/ billw2/pikrellcam). Finally, RPi Cam Web Interface (elinux.org/RPiCam-Web-Interface) is another web interface for the Raspberry $\mathrm{Pi}$ Camera module that provides high configurability and can be used for a wide variety of applications.

\section{7 | Recording and playing audio}

Increasingly Raspberry Pi's are used as part of acoustic monitoring systems that record continuously or in response to acoustic triggers, as well as an audio-playback device. The Raspberry Pi does not have any analogue input ports. To overcome this, you can make use of dedicated USB audio cards (e.g. Creative Sound Blaster) or audio HATs (e.g. IQaudio DAC+, Pisound) to connect a variety of microphones and record and play audio up to 24-bit and $196 \mathrm{KHz}$. It is also possible to directly connect a USB or Bluetooth microphone to the Raspberry Pi. Audio can be played back via the HDMI ports or the headphone jack, and passive stereo speakers can be connected by means of an amplifier (HAT), such as the IQaudio DigiAMP+. For high-quality playback a dedicated audio card or HAT s recommended. As an alternative to Raspberry Pi-based systems, some dedicated open acoustic devices exist, such as the Audiomoth (Hill et al., 2018).

\section{8 | Using electronic sensors and controllers}

The Raspberry Pi can connect with and control a huge range of electronics via its GPIO pins. Sensors that may be connected can measure a wide range of variables, including temperature, motion, sound, touch, light, humidity, moisture and $\mathrm{CO}_{2}$, and controllers range from simple buttons, switches and joysticks, to controllable LEDs, stepper motors, servos and Peltier elements to peristaltic pumps. The Raspberry Pi can only provide very limited low-voltage current to external devices via its GPIO ports. Relays make it possible to control the power ( $D C$ and $A C$ ) provided to other electronics that require much higher voltages and currents (both DC and AC; see Table S2 for a detailed guide). For example, one can use the Raspberry $\mathrm{Pi}$ to monitor water temperature and turn on a Peltier element to heat up the water when the temperature drops below a certain threshold. Although connecting and working with sensors and controllers requires some knowledge of electronics, it is not too difficult to get started using a breadboard and jumper wires, and a large number of online tutorials can be found online (for a temperature monitoring tutorial see Table S2). An easier solution might be to use the GrovePi HAT (from Seeedstudio), which makes connecting sensors almost as simple as plug-and-play.

It is also possible to read RFID tags with the Raspberry Pi. Although a range of commercially available animal RFID tags and readers are available, these cannot (easily) be integrated into custom applications due to their proprietary nature. However, a number of suppliers, including Loligo Systems, Cogniot, Eccel and Sparkfun, produce RFID HATs for the Raspberry Pi that can read ISO 11784 certified PIT tags for animal identification (at both $125 \mathrm{kHz}$ and $134.2 \mathrm{kHz}$ ), and are already available for less than $€ 1 /$ tag. This offers a wide range of possible experimental manipulations, where unique individuals are automatically detected and in turn these detections can be programmed to trigger specific actions, including playback of audio or visual stimuli, controlling servos and providing commands to external devices (see Bolaños et al., 2017; Chimento et al., 2021; Noorshams et al., 2017; Silasi et al., 2018; Youngblood, 2020). 


\section{9 | Programming with the Raspberry Pi}

One can get the most out of the Raspberry $\mathrm{Pi}$ by writing custom scripts to help control and automate tasks. Although the Raspberry Pi OS provides an easy-to-use Desktop interface, one will likely do most with their Raspberry Pi using the terminal. Although it is trickier to use, it gives much more control over the Raspberry $\mathrm{Pi}$ and its capabilities (for an overview of the essential commands, see Table S2). The Raspberry Pi OS also comes with a variety of programming and scripting languages such as Python, allowing for easy automated control of a wide range of sensors and devices. Users can thereby have scripts start automatically upon boot and run in the background (for tutorial, see Table S2). The Raspberry Pi can also be programmed to send automatic email, text, twitter and slack messages (for tutorials, see Table S2), which can be very helpful to get daily updates or specific warning messages, such as in the case of system failures. With a bit of programming knowledge, it is also possible to create a graphical user interface (GUI) to create custom control over the Raspberry Pi and connected electronics. This can range from very simple interfaces, such as to turn lights on or off or start a timer, to more advanced options, such as to configure recording parameters, show sensor data, or control experiments (see Figure 6). The best place to start is to use Python and one of the TKinter, PyQt and OpenCV libraries.

\subsection{0 | Storing and transferring data}

The microSD card holding the Raspberry $\mathrm{Pi}$ operating system also stores all user data. At the time of writing, microSD cards up of $256 \mathrm{~GB}$ are already available for less than $€ 50$. This makes it a simple solution for data storage, such as for field solutions. To read the data from the SD card, however, requires some extra steps on Mac and Windows operating systems. The Raspberry Pi can also write data to an external hard drive or USB stick connected to the USB port (for tutorials see Table S2). Note, however, that this will draw current, which is not ideal for battery-powered solutions. When on the same network, you can also access the data of the Raspberry Pi by mounting it as a network drive (for a file sharing tutorial, see Table S2). As a matter of fact, in the same way, the Raspberry Pi can be set up as a NAS server, providing a cheap alternative to commercial products. The Raspberry Pi can also mount a network drive, which can be a dedicated NAS server or a folder on another networked computer, that can be used for automatic storage and backup solutions. Such a central storage unit is especially helpful when working with an array of connected Raspberry Pi's. Rsync is a great tool to help the automatic transfer of files over the network via $\mathrm{SSH}$, while rclone (rclone.org) makes it possible to interact with cloud storage services (e.g. Google drive, Dropbox) from the command line and automatically send data using custom scripts (for a tutorial, see Table S2). This can also be very beneficial for remote recording units that still have internet access, such as those connected by means of a mobile network dongle.

\subsection{1 | Other considerations}

Someone starting to work with Raspberry Pi's should consider the potential dangers that exist when working with electronics. This is especially the case when building custom electronic circuits and using relays, in particular with higher voltage devices. The Raspberry $\mathrm{Pi}$ itself is quite rugged for a bare circuit board, both electronically and mechanically, but is still easy to damage or short circuit. It is therefore highly recommended to protect it with a suitable case. Also, always make sure that the Raspberry Pi can dissipate its heat. This is especially important for the newer, more powerful models, but also external conditions should be considered. For example, the Raspberry Pi should not be kept in a protective housing or box that retains the heat and receives a lot of direct sunlight. Dedicated heat sinks and small fan modules are available to help prevent overheating. The Raspberry Pi may still work after water exposure, especially when not plugged-in and the unit is thoroughly dried afterwards. Silica gel bags in the housing may also help reduce potential water damage, such as may also be caused by condensation. A Raspberry $\mathrm{Pi}$ can be left to run continuously $24 / 7$, just always make sure that you use a good quality power supply that provides enough amperage. A shortcoming of the Raspberry $\mathrm{Pi}$ is that it does not have a realtime clock (RTC) and only updates the time when connected to the
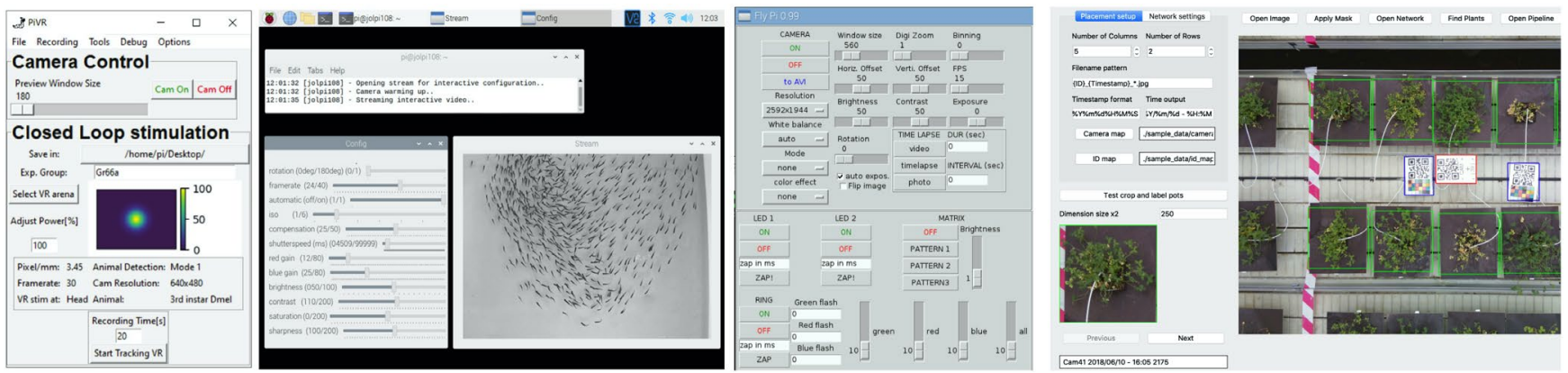

FIGURE 6 Various custom-build Graphical User Interfaces (GUIs) for controlling the Raspberry Pi in an easy-to-use, standardised way, from left to right: PiVR (Tadres \& Louis, 2020); pirecorder (Jolles, 2020); FlyPi (Maia Chagas et al., 2017) and Greenotyper (Tausen et al., 2020) 
internet. A RTC module is therefore recommended for projects without an internet connection (for tutorial, see Table S2). Instructions and code for applications can be easily shared, which will greatly enhance their accessibility and also help improve the repeatability and reproducibility of research. Over the years, the Raspberry $\mathrm{Pi}$ foundation put a lot of effort in making the Raspberry Pi accessible to anyone, including people without any coding or electronics experience. But users should be ready to put in some effort and trial and error learning to set up their system properly. Luckily a large number of online tutorials are available to get started, including $30+$ on the website associated with this paper (raspberrypi-guide.github. io; see Table S2). When stuck, there is a large, dedicated online community of educators, hobbyists and other researchers that can be called upon for troubleshooting. The best way to start is to search your specific issue online to see if others have also encountered and solved it, or post a message on a one of the community support forums, such as raspberrypi.stackexchange.com and raspberrypi.org/ forums/. Finally, mishaps can always happen, especially in the field. Therefore, before the actual experiment or field study, make sure the device is thoroughly tested, including exposing it to realistic environmental conditions, and incorporate enough time to fix potential technical issues or replace parts.

\section{6 | CONCLUDING REMARKS}

By reviewing the use of Raspberry Pi's across the biological domain, it is clear that these low-cost devices are already being widely used and that a hugely diverse range of applications exist, including nestbox monitoring, wildlife camera trapping, high-throughput behavioural recordings, animal home-cage monitoring, large-scale plant phenotyping, laboratory and greenhouse monitoring, underwater video and surveillance, fluorescent microscopy, virtual reality experiments, low-cost integrated RFID-tag solutions, field audio recording, automated playback devices, autonomous operant learning devices and long-term ecosystem monitoring. It is also apparent however, that despite the high diversity of applications, the Raspberry $\mathrm{Pi}$ is not yet widely used (or potentially known) by the broader biological community, but the increasing number of papers that mention the use of Raspberry Pi every year suggests this is increasing.

The Raspberry Pi is a solid, easy-to-use, low-cost tool that should be use to almost any biologist, from providing simple solutions to sophisticated autonomous devices, in the laboratory, the field and in the classroom. Its low-cost, large user community and high flexibility also make the Raspberry $\mathrm{Pi}$ a great tool for citizen science and scientific outreach, such as for interactive installations and artistic demonstrations (e.g. School of Lights, J.W.J; sonic kayaks, Griffiths et al., 2017). More generally, working with the Raspberry Pi, including learning to program and setting up electronics, is a fun and highly rewarding experience, and time invested in these skills will pay off dividends both within and outside of academia.

By reviewing applications across the biological domain (see Table S1 for a detailed overview of all included papers), and providing guidelines, pointers and an easy-to-use tutorial website (raspberryp i-guide.github.io), I aim to further stimulate the uptake of Raspberry Pi's. I hope to thereby help overcome the technology gap experienced by many researchers (Maia Chagas, 2018) and contribute to the democratisation of science (Ravindran, 2020). I believe open electronics like the Raspberry Pi can ultimately help revolutionise the collection of ecological, behavioural and environmental data, which will help push the boundaries of science, and advance our understanding of biology from the micro- to the macro-scale.

\section{ACKNOWLEDGEMENTS}

I want to thank Michael Oellermann, Neeltje Boogert, Shaun Killen and Andrew King, and two anonymous reviewers for helpful feedback, and all the people who attended my Raspberry Pi workshop at the 2019 ASAB conference in Konstanz for discussion. I also want to thank the Raspberry Pi Foundation for developing the Raspberry Pi. I am grateful for financial support from the Alexander von HumboldtStiftung, the Zukunfstkolleg, Institute for Advanced Study at the University of Konstanz and the Dr. J.L. Dobberke Foundation. I declare I have no competing financial interests or personal relationships related to the contents reported in this paper.

\section{PEER REVIEW}

The peer review history for this article is available at https://publo ns.com/publon/10.1111/2041-210X.13652.

\section{DATA AVAILABILITY STATEMENT}

This paper does not contain any data. A detailed overview of all reviewed empirical studies can be found in Supporting Information (Table S1).

\section{ORCID}

Jolle W. Jolles (iD https://orcid.org/0000-0001-9905-2633

\section{REFERENCES}

Ai, H., Kobayashi, Y., Matake, T., Takahashi, S., Hashimoto, K., Maeda, S., \& Tsuruta, N. (2017). Development of honeybee waggle dance and its differences between recruits and scouts. BioRxiv, https://doi. org/10.1101/179408

Alarcón-Nieto, G., Graving, J. M., Klarevas-Irby, J. A., MaldonadoChaparro, A. A., Mueller, I., \& Farine, D. R. (2018). An automated barcode tracking system for behavioural studies in birds. Methods in Ecology and Evolution, 9(6), 1536-1547. https://doi. org/10.1111/2041-210X.13005

Allan, B. M., Nimmo, D. G., lerodiaconou, D., VanDerWal, J., Koh, L. P., \& Ritchie, E. G. (2018). Futurecasting ecological research: The rise of technoecology. Ecosphere, 9(5), e02163. https://doi.org/10.1002/ ecs2.2163

Anderson, K., \& Gaston, K. J. (2013). Lightweight unmanned aerial vehicles will revolutionize spatial ecology. Frontiers in Ecology and the Environment, 11(3), 138-146. https://doi.org/10.1890/120150

Arce, W., \& Stevens, J. R. (2020). Developing a computer-controlled treat dispenser for canine operant conditioning. Journal of Open Hardware, 4(1), 6. https://doi.org/10.5334/joh.27

Ardesch, D. J., Balbi, M., \& Murphy, T. H. (2017). Automated touch sensing in the mouse tapered beam test using Raspberry $\mathrm{Pi}$. Journal of 
Neuroscience Methods, 291, 221-226. https://doi.org/10.1016/j. jneumeth.2017.08.030

Arts, K., van der Wal, R., \& Adams, W. M. (2015). Digital technology and the conservation of nature. Ambio, 44, 661-673. https://doi. org/10.1007/s13280-015-0705-1

Baden, T., Maia Chagas, A., Gage, G., Marzullo, T., Prieto-Godino, L. L., \& Euler, T. (2015). Open labware: 3-D printing your own lab equipment. PLOS Biology, 13(3), e1002086. https://doi.org/10.1371/journ al.pbio.1002086

Bardunias, P. M., Calovi, D. S., Carey, N., Soar, R., Turner, J. S., Nagpal, R., \& Werfel, J. (2020). The extension of internal humidity levels beyond the soil surface facilitates mound expansion in Macrotermes. Proceedings of the Royal Society B: Biological Sciences, 287, 20200894. https://doi.org/10.1098/rspb.2020.0894rspb20200894

Barlow, S. E., \& O'Neill, M. A. (2020). Technological advances in field studies of pollinator ecology and the future of e-ecology. Current Opinion in Insect Science, 38, 15-25. https://doi.org/10.1016/j.cois.2020.01.008

Beason, R. D., Riesch, R., \& Koricheva, J. (2019). AURITA: An affordable, autonomous recording device for acoustic monitoring of audible and ultrasonic frequencies. Bioacoustics, 28(4), 381-396. https://doi. org/10.1080/09524622.2018.1463293

Beattie, R., Hippenmeyer, S., \& Pauler, F. M. (2020). SCOPES: Sparking curiosity through open-source platforms in education and science. Frontiers in Education, 5(May), 48. https://doi.org/10.3389/ feduc. 2020.00048

Bjerge, K., Nielsen, J. B., Sepstrup, M. V., Helsing-Nielsen, F., \& Høye, T. T. (2021). An automated light trap to monitor moths (Lepidoptera) using computer vision-based tracking and deep learning. Sensors, 21(2), 118. https://doi.org/10.3390/s21020343

Bolaños, F., LeDue, J. M., \& Murphy, T. H. (2017). Cost effective raspberry pi-based radio frequency identification tagging of mice suitable for automated in vivo imaging. Journal of Neuroscience Methods, 276, 79-83. https://doi.org/10.1016/j.jneumeth.2016.11.011

Bontpart, T., Concha, C., Giuffrida, M. V., Robertson, I., Admkie, K., Degefu, T., Girma, N., Tesfaye, K., Haileselassie, T., Fikre, A., Fetene, M., Tsaftaris, S. A., \& Doerner, P. (2020). Affordable and robust phenotyping framework to analyse root system architecture of soil-grown plants. Plant Journal, 103(6), 2330-2343. https://doi. org/10.1111/tpj.14877

Bradfer-Lawrence, T., Gardner, N., Bunnefeld, L., Bunnefeld, N., Willis, S. G., \& Dent, D. H. (2019). Guidelines for the use of acoustic indices in environmental research. Methods in Ecology and Evolution, 10(10), 1796-1807. https://doi.org/10.1111/2041-210X.13254

Brem, E. A., McNulty, A. D., \& Israelsen, W. J. (2020). Breeding and hibernation of captive meadow jumping mice (Zapus hudsonius). BioRxiv, https://doi.org/10.1101/2020.10.02.323386

Buscher, N., Ojeda, A., Francoeur, M., Hulyalkar, S., Claros, C., Tang, T., Terry, A., Gupta, A., Fakhraei, L., \& Ramanathan, D. S. (2020). Opensource raspberry $\mathrm{Pi}$-based operant box for translational behavioral testing in rodents. Journal of Neuroscience Methods, 342, 108761. https://doi.org/10.1016/j.jneumeth.2020.108761

Cabaccan, C. N., Cruz, F. R. G., \& Agulto, I. C. (2017). Nanotechnology, information technology, communication and control, environment and management. 9th International Conference on Humanoid, 1-5. https://doi.org/10.1109/HNICEM.2017.8269427

Caldas-Morgan, M., Alvarez-Rosario, A., \& Rodrigues Padovese, L. (2015). An autonomous underwater recorder based on a single board computer. PLoS ONE, 10(6), e0130297. https://doi.org/10.1371/ journal.pone.0130297

Charlton, H. R., \& Merritt, D. J. (2020). Carbon dioxide-induced bioluminescence increase in Arachnocampa larvae. Journal of Experimental Biology, 223, jeb225151. https://doi.org/10.1242/jeb.225151

Chave, J. (2013). The problem of pattern and scale in ecology: What have we learned in 20 years? Ecology Letters, 16, 4-16. https://doi. org/10.1111/ele.12048
Chimento, M., Alarcón-Nieto, G., \& Aplin, L. M. (2021). Population turnover facilitates cultural selection for efficiency in birds. Current Biology, 31(11), 2477-2483.e3. https://doi.org/10.1016/j. cub.2021.03.057

Churchill, E. R., Bridle, J. R., \& Thom, M. D. F. (2020). Spatially clustered resources increase male aggregation and mating duration in Drosophila melanogaster. Animal Behaviour, 169, 45-50. https://doi. org/10.1016/j.anbehav.2020.09.002

Dell, A. I., Bender, J. A., Branson, K., Couzin, I. D., de Polavieja, G. G., Noldus, L. P. J. J., Pérez-Escudero, A., Perona, P., Straw, A. D., Wikelski, M., \& Brose, U. (2014). Automated image-based tracking and its application in ecology. Trends in Ecology \& Evolution, 29(7), 417-428. https://doi.org/10.1016/j.tree.2014.05.004

Dobrescu, A., Scorza, L. C. T., Tsaftaris, S. A., \& McCormick, A. J. (2017). A 'Do-It-Yourself' phenotyping system: Measuring growth and morphology throughout the diel cycle in rosette shaped plants. Plant Methods, 13(1), 1-12. https://doi.org/10.1186/s13007-017-0247-6

Dolgin, E. (2018). How to start a lab when funds are tight career-feature. Nature, 559(7713), 291-293. https://doi.org/10.1038/d41586-01805655-3

Dröge, S., Martin, D. A., Andriafanomezantsoa, R., Burivalova, Z., Fulgence, T. R., Osen, K., Rakotomalala, E., Schwab, D., Wurz, A., Richter, T., \& Kreft, H. (2021). Listening to a changing landscape: Acoustic indices reflect bird species richness and plot-scale vegetation structure across different land-use types in northeastern Madagascar. Ecological Indicators, 120, 106929. https://doi. org/10.1016/j.ecolind.2020.106929

Ferreira, A. C., Silva, L. R., Renna, F., Brandl, H. B., Renoult, J. P., Farine, D. R., Covas, R., \& Doutrelant, C. (2020). Deep learning-based methods for individual recognition in small birds. Methods in Ecology and Evolution, 11(9), 1072-1085. https://doi.org/10.1111/2041-210X.13436

Fletcher, A. C., \& Mura, C. (2019). Ten quick tips for using a raspberry Pi. PLoS Computational Biology, 15(5), 1-11. https://doi.org/10.1371/ journal.pcbi.1006959

Freckleton, R. P., \& lossa, G. (2010). Editorial: Methods in ecology and evolution. Methods in Ecology and Evolution, 1, 1-2. https://doi. org/10.1111/j.2041-210X.2010.00016.x

Gaggion, N., Ariel, F., Daric, V., Lambert, É., Legendre, S., Roulé, T., Camoirano, A., Milone, D. H., Crespi, M., Blein, T., \& Ferrante, E. (2020). ChronoRoot: High-throughput phenotyping by deep segmentation networks reveals novel temporal parameters of plant root system architecture. BioRxiv, https://doi.org/10.1101/2020.10.27. 350553

Geissmann, Q., Garcia Rodriguez, L., Beckwith, E. J., French, A. S., Jamasb, A. R., \& Gilestro, G. F. (2017). Ethoscopes: An open platform for highthroughput ethomics. PLOS Biology, 15(10), e2003026. https://doi. org/10.1371/journal.pbio.2003026

Ghosh, S., Watson, A., Gonzalez-Navarro, O. E., Ramirez-Gonzalez, R. H., Yanes, L., Mendoza-Suárez, M., Simmonds, J., Wells, R., Rayner, T., Green, P., Hafeez, A., Hayta, S., Melton, R. E., Steed, A., Sarkar, A., Carter, J., Perkins, L., Lord, J., Tester, M., ... Hickey, L. T. (2018). Speed breeding in growth chambers and glasshouses for crop breeding and model plant research. Nature Protocols, 13(12), 2944-2963. https:// doi.org/10.1038/s41596-018-0072-z

Griffiths, A. G. F., Garrett, J. K., Duffy, J. P., Matthews, K., Visi, F. G., Eatock, C., Robinson, M., \& Griffiths, D. J. (2020). New water and air pollution sensors added to the Sonic Kayak citizen science system for low cost environmental mapping. BioRxiv, https://doi. org/10.1101/2020.11.03.366229

Griffiths, A. G. F., Kemp, K. M., Matthews, K., Garrett, J. K., \& Griffiths, D. J. (2017). Sonic Kayaks: Environmental monitoring and experimental music by citizens. PLoS Biology, 15(11), 1-10. https://doi.org/10.1371/ journal.pbio. 2004044

Grindstaff, B., Mabry, M. E., Blischak, P. D., Quinn, M., \& Chris Pires, J. (2019). Affordable remote monitoring of plant growth in facilities 
using Raspberry Pi computers. Applications in Plant Sciences, 7(8), 18. https://doi.org/10.1002/aps3.11280

Gurdita, A., Vovko, H., \& Ungrin, M. (2016). A simple and low-cost monitoring system to investigate environmental conditions in a biological research laboratory. PLoS ONE, 11(1), 1-10. https://doi.org/10.1371/ journal.pone. 0147140

Gurley, K. (2019). Two open source designs for a low-cost operant chamber using Raspberry $\mathrm{Pi}^{\mathrm{TM}}$. Journal of the Experimental Analysis of Behavior, 111(3), 508-518. https://doi.org/10.1002/jeab.520

Hebert, P. D. N., Cywinska, A., Ball, S. L., \& DeWaard, J. R. (2003). Biological identifications through DNA barcodes. Proceedings of the Royal Society of London. Series B: Biological Sciences, 270(1512), 313321. https://doi.org/10.1098/rspb.2002.2218

Hermann, A., Chladek, J., \& Stepputtis, D. (2020). iFO (infrared Fish Observation) - An open source low-cost infrared underwater video system. HardwareX, 8, e00149. https://doi.org/10.1016/j.ohx.2020. e00149

Heuschele, J., Lode, T., Andersen, T., \& Titelman, J. (2020). The hidden dimension: Context-dependent expression of repeatable behavior in copepods. Environmental Toxicology and Chemistry, 39(5), 1017-1026. https://doi.org/10.1002/etc.4688

Hill, A. P., Prince, P., Piña Covarrubias, E., Doncaster, C. P., Snaddon, J. L., Rogers, A., Prince, P., Piña, E., Patrick, C. C., Rogers, A., Hill, A. P., Piña Covarrubias, E., Doncaster, C. P., Snaddon, J. L., \& Rogers, A. (2018). AudioMoth: Evaluation of a smart open acoustic device for monitoring biodiversity and the environment. Methods in Ecology and Evolution, 9(5), 1199-1211. https://doi.org/10.1111/2041-210X.12955

Hol, F. J., Lambrechts, L., \& Prakash, M. (2020). BiteOscope, an open platform to study mosquito biting behavior. eLife, 9, 2020.02.19.955641. https://doi.org/10.7554/eLife.56829

Hughey, L. F., Hein, A. M., Strandburg-Peshkin, A., \& Jensen, F. H. (2018). Challenges and solutions for studying collective animal behaviour in the wild. Philosophical Transactions of the Royal Society B: Biological Sciences, 373(1746), 1-13. https://doi.org/10.1098/rstb.2017.0005

Jaime, M. D. L. A., Karott, S., Salem, G. H., Krynitsky, J., GarmendiaCedillos, M., Anderson, S., Harbison, S., Pohida, T. J., \& Oliver, B. (2018). The high-throughput WAFFL system for treating and monitoring individual Drosophila melanogaster adults. BioRxiv, https://doi. org/10.1101/428037

Johnson, K. M., Brodersen, C., Carins-Murphy, M. R., Choat, B., \& Brodribb, T. J. (2020). Xylem embolism spreads by single-conduit events in three dry forest angiosperm stems. Plant Physiology, 184(1), 212-222. https://doi.org/10.1104/PP.20.00464

Johnson, Z. V., Arrojwala, M. T. S., Aljapur, V., Lee, T., Lancaster, T. J., Lowder, M. C., Gu, K., Stockert, J. I., Lecesne, R. L., Moorman, J. M., Streelman, J. T., \& McGrath, P. T. (2020). Automated measurement of long-term bower behaviors in Lake Malawi cichlids using depth sensing and action recognition. Scientific Reports, 10(1), 1-15. https:// doi.org/10.1038/s41598-020-77549-2

Jolles, J. (2020). pirecorder: Controlled and automated image and video recording with the Raspberry $\mathrm{Pi}$. Journal of Open Source Software, 5(54), 2584. https://doi.org/10.21105/joss.02584

Jolles, J. W., Boogert, N. J., Sridhar, V. H., Couzin, I. D., \& Manica, A. (2017). Consistent individual differences drive collective behavior and group functioning of schooling fish. Current Biology, 27(18), 2862-2868. https://doi.org/10.1016/j.cub.2017.08.004

Jolles, J. W., Briggs, H. D., Araya-Ajoy, Y. G., \& Boogert, N. J. (2019). Personality, plasticity and predictability in sticklebacks: Bold fish are less plastic and more predictable than shy fish. Animal Behaviour, 154, 193-202. https://doi.org/10.1016/j.anbehav.2019.06.022

Jolles, J. W., Mazué, G. P. F., Davidson, J., Behrmann-Godel, J., \& Couzin, I. D. (2020). Schistocephalus parasite infection alters sticklebacks' movement ability and thereby shapes social interactions. Scientific Reports, 10(1), 12282. https://doi.org/10.1038/s41598-02069057-0
Jones, B. M., Rao, V. D., Gernat, T., Jagla, T., Cash-Ahmed, A. C., Rubin, B. E. R., Comi, T. J., Bhogale, S., Husain, S. S., Blatti, C., Middendorf, M., Sinha, S., Chandrasekaran, S., \& Robinson, G. E. (2020). Individual differences in honey bee behavior enabled by plasticity in brain gene regulatory networks. eLife, 9, 1-28. https://doi.org/10.7554/ eLife.62850

Jones, D. (2018). Picamera 1.13 Documentation. Retrieved from https:// picamera.readthedocs.io/en/release-1.13/

Kallmyer, N. E., Shin, H. J., Brem, E. A., Israelsen, W. J., \& Reuel, N. F. (2019). Nesting box imager: Contact-free, real-time measurement of activity, surface body temperature, and respiratory rate applied to hibernating mouse models. PLOS Biology, 17(7), e3000406. https:// doi.org/10.1371/journal.pbio.3000406

Kays, R., Crofoot, M. C., Jetz, W., \& Wikelski, M. (2015). Terrestrial animal tracking as an eye on life and planet. Science, 348(6240), aaa2478. https://doi.org/10.1126/science.aaa2478

Kwok, R. (2017). Build it yourself. Nature, 545(7653), 253-255. https:// doi.org/10.1038/nj7653-253a

Leitch, K., Ponce, F., van Breugel, F., \& Dickinson, M. H. (2020). The long-distance flight behavior of Drosophila suggests a general model for wind-assisted dispersal in insects. BioRxiv, https://doi. org/10.1101/2020.06.10.145169

Lendvai, Á. Z., Akçay, Ç., Weiss, T., Haussmann, M. F., Moore, I. T., \& Bonier, F. (2015). Low cost audiovisual playback and recording triggered by radio frequency identification using Raspberry Pi. PeerJ, 2015(4), 1-11. https://doi.org/10.7717/peerj.877

Lertvilai, P. (2020). The In situ Plankton Assemblage eXplorer (IPAX): An inexpensive underwater imaging system for zooplankton study. Methods in Ecology and Evolution, 11(9), 1042-1048. https://doi. org/10.1111/2041-210X.13441

Longley, M., Willis, E. L., Tay, C. X., \& Chen, H. (2017). An open source device for operant licking in rats. PeerJ, 2017(2), 1-15. https://doi. org/10.7717/peerj.2981

Lucon-Xiccato, T., Manabe, K., \& Bisazza, A. (2019). Guppies learn faster to discriminate between red and yellow than between two shapes. Ethology, 125(2), 82-91. https://doi.org/10.1111/eth.12829

Maia Chagas, A. (2018). Haves and have nots must find a better way: The case for open scientific hardware. PLoS Biology, 16(9), e3000014. https://doi.org/10.1371/journal.pbio.3000014

Maia Chagas, A., Prieto-Godino, L. L., Arrenberg, A. B., \& Baden, T. (2017). The $€ 100$ lab: A 3D-printable open-source platform for fluorescence microscopy, optogenetics, and accurate temperature control during behaviour of zebrafish, Drosophila, and Caenorhabditis elegans. PLOS Biology, 15(7), e2002702. https://doi.org/10.1371/ journal.pbio. 2002702

Marshall, H. H., Griffiths, D. J., Mwanguhya, F., Businge, R., Griffiths, A. G. F., Kyabulima, S., Mwesige, K., Sanderson, J. L., Thompson, F. J., Vitikainen, E. I. K., \& Cant, M. A. (2018). Data collection and storage in long-term ecological and evolutionary studies: The mongoose 2000 system. PLoS ONE, 13(1), 1-15. https://doi.org/10.1371/journ al.pone. 0190740

Martorell-Barceló, M., Mulet, J., Sanllehi, J., Signaroli, M., Lana, A., Barcelo-Serra, M., Aspillaga, E., \& Alós, J. (2021). Aggressivenessrelated behavioural types in the pearly razorfish. PeerJ, 9, e10731. https://doi.org/10.7717/peerj.10731

McBride, W. J., \& Courter, J. R. (2019). Using Raspberry Pi microcomputers to remotely monitor birds and collect environmental data. Ecological Informatics, 54, 101016. https://doi.org/10.1016/j. ecoinf.2019.101016

Meniri, M., Farley, A., Helfenstein, F., \& Fasel, N. (2019). A guide for ecologists to build a low-cost selective trap using radio frequency identification detection. Behavioral Ecology and Sociobiology, 73(6), 80. https://doi.org/10.1007/s00265-019-2675-y

Miller, E. R. (2015). Improve undergraduate science education. Nature, 523(7560), 282-284. 
Minervini, M., Giuffrida, M. V., Perata, P., \& Tsaftaris, S. A. (2017). Phenotiki: An open software and hardware platform for affordable and easy image-based phenotyping of rosette-shaped plants. Plant Journal, 90(1), 204-216. https://doi.org/10.1111/tpj.13472

Mouy, X., Black, M., Cox, K., Qualley, J., Mireault, C., Dosso, S., \& Juanes, F. (2020). FishCam: A low-cost open source autonomous camera for aquatic research. HardwareX, 8, e00110. https://doi.org/10.1016/j. ohx.2020.e00110

Myers, D., Berg, H., \& Maneas, G. (2019). Comparing the soundscapes of organic and conventional olive groves: A potential method for bird diversity monitoring. Ecological Indicators, 103, 642-649. https://doi. org/10.1016/j.ecolind.2019.04.030

Nazir, S., Newey, S., Justin Irvine, R., Verdicchio, F., Davidson, P., Fairhurst, G., \& Van Der Wal, R. (2017). WiseEye: Next generation expandable and programmable camera trap platform for wildlife research. PLoS ONE, 12(1), 1-15. https://doi.org/10.1371/journal.pone.0169758

Noorshams, O., Boyd, J. D., \& Murphy, T. H. (2017). Automating mouse weighing in group homecages with Raspberry Pi micro-computers. Journal of Neuroscience Methods, 285, 1-5. https://doi.org/10.1016/j. jneumeth.2017.05.002

Nuñez, I., Matute, T., Herrera, R., Keymer, J., Marzullo, T., Rudge, T., \& Federici, F. (2017). Low cost and open source multi-fluorescence imaging system for teaching and research in biology and bioengineering. PLoS ONE, 12(11), 1-21. https://doi.org/10.1371/journ al.pone. 0187163

O'Leary, J. D., O'Leary, O. F., Cryan, J. F., \& Nolan, Y. M. (2018). A lowcost touchscreen operant chamber using a Raspberry $\mathrm{Pi}^{\mathrm{TM}}$. Behavior Research Methods, 50(6), 2523-2530. https://doi.org/10.3758/s1342 8-018-1030-y

Pasquali, V., D'Alessandro, G., Gualtieri, R., \& Leccese, F. (2017). A new data logger based on Raspberry-Pi for Arctic Notostraca locomotion investigations. Measurement, 110, 249-256. https://doi. org/10.1016/j.measurement.2017.07.004

Pearce, J. M. (2014). Open-source lab: How to build your own hardware and reduce research costs. Elsevier.

Phillips, B. T., Licht, S., Haiat, K. S., Bonney, J., Allder, J., Chaloux, N., Shomberg, R., \& Noyes, T. J. (2019). DEEPi: A miniaturized, robust, and economical camera and computer system for deep-sea exploration. Deep-Sea Research Part I, 153, 103136. https://doi. org/10.1016/j.dsr.2019.103136

Philson, C., Ray, A., Foltz, S., \& Davis, J. (2018). Programmable Automated System for Songbird Ecobehavioral Research (PASSER): Using flexible computer-integrated feeders to conduct high resolution studies of environment-behavior dynamics in songbirds. Ecology and Evolution, 8(24), 12522-12532. https://doi.org/10.1002/ece3.4638

Pimm, S. L., Alibhai, S., Bergl, R., Dehgan, A., Giri, C., Jewell, Z., Joppa, L., Kays, R., \& Loarie, S. (2015). Emerging technologies to conserve biodiversity. Trends in Ecology \& Evolution, 30(11), 685-696. https:// doi.org/10.1016/j.tree.2015.08.008

Pollina, T., Larson, A. G., Lombard, F., Li, H., Colin, S., de Vargas, C., \& Prakash, M. (2020). PlanktonScope: Affordable modular imaging platform for citizen oceanography. BioRxiv, 1-34. https://doi. org/10.1101/2020.04.23.056978

Prinz, A. C. B., Taank, V. K., Voegeli, V., \& Walters, E. L. (2016). A novel nest-monitoring camera system using a Raspberry Pi microcomputer. Journal of Field Ornithology, 87(4), 427-435. https://doi. org/10.1111/jofo.12182

Privitera, M., Ferrari, K. D., von Ziegler, L. M., Sturman, O., Duss, S. N., Floriou-Servou, A., Germain, P. L., Vermeiren, Y., Wyss, M. T., De Deyn, P. P., Weber, B., \& Bohacek, J. (2020). A complete pupillometry toolbox for real-time monitoring of locus coeruleus activity in rodents. Nature Protocols, 15(8), 2301-2320. https://doi.org/10.1038/ s41596-020-0324-6

Proppe, D. S., Pandit, M. M., Bridge, E. S., Jasperse, P., \& Holwerda, C. (2020). Semi-portable solar power to facilitate continuous operation of technology in the field. Methods in Ecology and Evolution, 11(11) 1388-1394. https://doi.org/10.1111/2041-210X.13456

Purser, A., Hoge, U., Lemburg, J., Bodur, Y., Schiller, E., Ludszuweit, J., Greinert, J., Dreutter, S., Dorschel, B., \& Wenzhöfer, F. (2020). PlasPI marine cameras: Open-source, affordable camera systems for time series marine studies. HardwareX, 7, e00102. https://doi. org/10.1016/j.ohx.2020.e00102

Raab, T., Bayezit, S., Erdle, S., \& Benda, J. (2021). Electric fish use electrocommunication signals to fine tune relative dominance and access to resources. BioRxiv, https://doi.org/10.1101/2021.02.04. 429572

Raspberry Pi Foundation. (2020). Raspberry Pi foundation annual review.

Ravindran, S. (2020). How DIY technologies are democratizing science. Nature, 587(7834), 509-511. https://doi.org/10.1038/d41586-02003193-5

Reardon, S. (2013). DIY diagnostics for world's poorest. New Scientist, 219(2933), 20-21. https://doi.org/10.1016/s0262-4079(13)62184-3

Reemeyer, J. E., \& Rees, B. B. (2020). Plasticity, repeatability and phenotypic correlations of aerobic metabolic traits in a small estuarine fish. The Journal of Experimental Biology, 223, jeb228098. https://doi. org $/ 10.1242 /$ jeb. 228098

Ripperger, S. P., Carter, G. G., Page, R. A., Duda, N., Koelpin, A., Weigel, R., Hartmann, M., Nowak, T., Thielecke, J., Schadhauser, M., Robert, J., Herbst, S., Meyer-Wegener, K., Wägemann, P., Schröder-Preikschat, W., Cassens, B., Kapitza, R., Dressler, F., \& Mayer, F. (2020). Thinking small: Next-generation sensor networks close the size gap in vertebrate biologging. PLOS Biology, 18(4), e3000655. https://doi. org/10.1371/journal.pbio.3000655

Saunders, J. L., \& Wehr, M. (2020). Autopilot: Automating behavioral experiments with lots of Raspberry Pis. BioRxiv, https://doi. org/10.1101/807693

Saxena, R., Barde, W., \& Deshmukh, S. S. (2018). Inexpensive, scalable camera system for tracking rats in large spaces. Journal of Neurophysiology, 120, 2383-2395. https://doi.org/10.1152/ jn.00215.2018

Sehdev, A., Mohammed, Y. G., Tafrali, C., \& Szyszka, P. (2019). Social foraging extends associative odor-food memory expression in an automated learning assay for Drosophila melanogaster. Journal of Experimental Biology, 222, jeb207241. https://doi.org/10.1242/ jeb. 207241

Sethi, S. S., Ewers, R. M., Jones, N. S., David, C. D. L., \& Picinali, L. (2018). Robust, real-time and autonomous monitoring of ecosystems with an open, low-cost, networked device. Methods in Ecology and Evolution, 9, 2383-2387. https://doi.org/10.1111/2041-210X. 13089

Sethi, S. S., Ewers, R. M., Jones, N. S., Signorelli, A., Picinali, L., \& Orme, C. D. L. (2020). SAFE Acoustics: An open-source, real-time ecoacoustic monitoring network in the tropical rainforests of Borneo. Methods in Ecology and Evolution, 11(10), 1182-1185. https://doi. org/10.1111/2041-210X.13438

Shah, N. P., \& Bhatt, P. P. (2017). Greenhouse automation and monitoring system design and implemenation. International Journal of Advanced Research in Computer Science, 8(9), 468-471. https://doi. org/10.26483/ijarcs.v8i9.4981

Signaroli, M. (2020). Automatic marine fish detection using deep learning under laboratory conditions. University of the Balearic Islands.

Silasi, G., Boyd, J. D., Bolanos, F., LeDue, J. M., Scott, S. H., \& Murphy, T. $\mathrm{H}$. (2018). Individualized tracking of self-directed motor learning in group-housed mice performing a skilled lever positioning task in the home cage. Journal of Neurophysiology, 119(1), 337-346. https://doi. org/10.1152/jn.00115.2017

Singh, S., Bermudez-Contreras, E., Nazari, M., Sutherland, R. J., \& Mohajerani, M. H. (2019). Low-cost solution for rodent homecage behaviour monitoring. PLoS ONE, 14(8), 1-18. https://doi. org/10.1371/journal.pone.0220751 
Snaddon, J., Petrokofsky, G., Jepson, P., \& Willis, K. J. (2013). Biodiversity technologies: Tools as change agents. Biology Letters, 9(1), 20121029. https://doi.org/10.1098/rsbl.2012.1029

Spierer, A. N., Yoon, D., Zhu, C.-T., \& Rand, D. M. (2021). FreeClimber: Automated quantification of climbing performance in Drosophila. The Journal of Experimental Biology, 224(2), jeb229377. https://doi. org/10.1242/jeb.229377

Stanton, L. A., Bridge, E. S., Huizinga, J., Johnson, S. R., Young, J. K., \& Benson-Amram, S. (2020). Variation in reversal learning by three generalist mesocarnivores. Animal Cognition, 24(3), 555-568. https:// doi.org/10.1007/s10071-020-01438-4

Tadres, D., \& Louis, M. (2020). PiVR: An affordable and versatile closed-loop platform to study unrestrained sensorimotor behavior. PLOS Biology, 18(7), e3000712. https://doi.org/10.1371/journ al.pbio.3000712

Tausen, M., Clausen, M., Moeskjær, S., Shihavuddin, A., Dahl, A. B., Janss, L., \& Andersen, S. U. (2020). Greenotyper: Image-based plant phenotyping using distributed computing and deep learning. Frontiers in Plant Science, 11, 1181. https://doi.org/10.3389/fpls.2020.01181

Todd, D. W., Philip, R. C., Niihori, M., Ringle, R. A., Coyle, K. R., Zehri, S. F., Zabala, L., Mudery, J. A., Francis, R. H., Rodriguez, J. J., \& Jacob, A. (2017). A fully automated high-throughput zebrafish behavioral ototoxicity assay. Zebrafish, 14(4), 331-342. https://doi.org/10.1089/ zeb.2016.1412

Tovar, J. C., Hoyer, J. S., Lin, A., Tielking, A., Callen, S. T., Elizabeth Castillo, S., Miller, M., Tessman, M., Fahlgren, N., Carrington, J. C., Nusinow, D. A., \& Gehan, M. A. (2018). Raspberry Pi-powered imaging for plant phenotyping. Applications in Plant Sciences, 6(3), 1-12. https://doi.org/10.1002/aps3.1031

Tu, G. J., Hansen, M. K., Kryger, P., \& Ahrendt, P. (2016). Automatic behaviour analysis system for honeybees using computer vision. Computers and Electronics in Agriculture, 122, 10-18. https://doi. org/10.1016/j.compag.2016.01.011

Valle, B., Simonneau, T., Boulord, R., Sourd, F., Frisson, T., Ryckewaert, M., Hamard, P., Brichet, N., Dauzat, M., \& Christophe, A. (2017). PYM: A new, affordable, image-based method using a Raspberry Pi to phenotype plant leaf area in a wide diversity of environments. Plant Methods, 13(1), 1-17. https://doi.org/10.1186/s13007-017-0248-5

Vickers, M., \& Schwarzkopf, L. (2016). A simple method to predict body temperature of small reptiles from environmental temperature. Ecology and Evolution, 6(10), 3059-3066. https://doi.org/10.1002/ ece3.1961

Wallace, K. J., Rausch, R. T., Ramsey, M. E., \& Cummings, M. E. (2020). Sex differences in cognitive performance and style across domains in mosquitofish (Gambusia affinis). Animal Cognition, 23(4), 655-669. https://doi.org/10.1007/s10071-020-01367-2

Wang, D., Forstmeier, W., Farine, D., Maldonado-Chaparro, A. A., Martin, K., Pei, Y., Alarcón-Nieto, G., Klarevas-Irby, J. A., Ma, S., Aplin, L.
M., \& Kempenaers, B. (2021). Machine learning reveals cryptic dialects that guide mate choice in a songbird. BioRxiv, https://doi. org/10.1101/2021.02.08.430277

Weber, W. D., \& Fisher, H. S. (2019). An inexpensive remotely-operated video recording system for continuous behavioral observations. BioRxiv, https://doi.org/10.1101/596106

Whitesides, G. M. (2011). The frugal way. The Economist.

Whytock, R. C., \& Christie, J. (2017). Solo: An open source, customizable and inexpensive audio recorder for bioacoustic research. Methods in Ecology and Evolution, 8, 308-312. https://doi. org/10.1111/2041-210X.12678

Wilhite, N. G., Howell, P. E., \& Martin, J. A. (2020). Evaluation of acoustic recording devices to survey northern bobwhite populations. Wildlife Society Bulletin, 44(1), 200-207. https://doi.org/10.1002/wsb.1061

Williams, K., De Robertis, A., Berkowitz, Z., Rooper, C., \& Towler, R. (2014). An underwater stereo-camera trap. Methods in Oceanography, 11, 1-12. https://doi.org/10.1016/j.mio.2015.01.003

Wilshin, S., Shamble, P. S., Hovey, K. J., Harris, R., Spence, A. J., \& Hsieh, S. T. (2018). Limping following limb loss increases locomotor stability. Journal of Experimental Biology, 221, jeb174268. https://doi. org/10.1242/jeb.174268

Wincott, M., Jefferson, A., Dobbie, I., Booth, M., Davis, I., \& Parton, R. (2020). Democratising 'Microscopi': A 3D printed automated XYZT fluorescence imaging system for teaching, outreach and fieldwork. Biorxiv, https://doi.org/10.1101/2020.05.21.108894

Wyse, S. V., Hulme, P. E., \& Holland, E. P. (2019). Partitioning intraspecific variation in seed dispersal potential using a lowcost method for rapid estimation of samara terminal velocity. Methods in Ecology and Evolution, 10(8), 1298-1307. https://doi. org/10.1111/2041-210X.13202

Youngblood, M. (2020). A Raspberry Pi-based, RFID-equipped birdfeeder for the remote monitoring of wild bird populations. Ringing \& Migration, (1), 1-8. https://doi.org/10.1080/03078698.2019.1759908

Zwetsloot, R. (2019). Benchmarking Raspberry Pi 4. The Magpi, 83, 32-35.

\section{SUPPORTING INFORMATION}

Additional supporting information may be found online in the Supporting Information section.

How to cite this article: Jolles, J. W. (2021). Broad-scale applications of the Raspberry Pi: A review and guide for biologists. Methods in Ecology and Evolution, 12, 1562-1579. https://doi.org/10.1111/2041-210X.13652 